Article

\title{
The Effect of Dietary Quercetin on the Glutathione Redox System and Small Intestinal Functionality of Weaned Piglets
}

\author{
Jeroen Degroote ${ }^{1, * \mathbb{C}}$, Hans Vergauwen ${ }^{2}$, Noémie Van Noten ${ }^{1}{ }^{\circledR}$, Wei Wang ${ }^{1}$, Stefaan De Smet ${ }^{1}$, \\ Chris Van Ginneken ${ }^{2}$ and Joris Michiels ${ }^{1}$ \\ 1 Laboratory of Animal Nutrition and Animal Product Quality (LANUPRO), Department of Animal Sciences \\ and Aquatic Ecology, Ghent University, Coupure Links 653, 9000 Ghent, Belgium \\ 2 Laboratory of Applied Veterinary Morphology, Department of Veterinary Sciences, University of Antwerp, \\ Universiteitsplein 1, 2610 Wilrijk, Belgium \\ * Correspondence: jerdgroo.degroote@ugent.be; Tel.: +32-9-264-9008
}

Received: 30 June 2019; Accepted: 11 August 2019; Published: 16 August 2019

\begin{abstract}
Quercetin has been shown to alleviate mucosal damage and modulate the glutathione (GSH) redox system in the colon of rodents. In the current study, we assessed whether quercetin was able to mitigate small intestinal dysfunction in weaned pigs. Here, 224 weaned piglets were fed a diet containing quercetin at either $0,100,300$, or $900 \mathrm{mg} / \mathrm{kg}$ diet until d14 post-weaning, followed by a common basal diet until d42. Eight animals per treatment were sampled at d5 and d14 post-weaning. In these animals, the small intestinal histomorphology, barrier function, and protein abundance of occludin, caspase-3, and proliferating cell nuclear antigen were assessed. None of these parameters were affected, and neither did quercetin improve performance up to $\mathrm{d} 42$ post-weaning. The GSH redox system was evaluated in blood, small intestinal mucosa, and liver. Quercetin did not affect the glutathione peroxidase, glutathione reductase, and glutamate-cysteine ligase activity in these tissues. In contrast, the hepatic glutathione transferase (GST) activity was significantly increased by quercetin supplementation at $\mathrm{d} 5$ post-weaning of 100,300 , and $900 \mathrm{mg} / \mathrm{kg}$. Importantly, d5 was characterized by a more oxidized GSH redox status. To conclude, dietary quercetin had little effect on the small intestine, but did upregulate hepatic GST in the occurrence of redox disturbance.
\end{abstract}

Keywords: weaned pigs; quercetin; glutathione; redox status; small intestine

\section{Introduction}

Quercetin, as the foremost representative of flavonols, has been extensively investigated for its beneficial effects on health [1]. With regard to the gastrointestinal tract, quercetin received a lot of attention in treating chronic intestinal inflammation. Different mechanisms, including protection against oxidative stress, preservation of epithelial barrier function, and immunomodulatory properties in the gut, are believed to be involved [2,3]. These biological effects could be valuable in weaned piglets, since these animals suffer from a disturbed gastrointestinal functionality during the first two weeks after weaning. Villus atrophy-mucosal barrier dysfunction in the small intestine-co-occurs with a state of acute inflammation and immune stimulation [4-6]. Therapy in weaned piglets mainly relies on the use of zinc and copper beyond nutritional requirements and the excessive use of antimicrobials. This raises major concerns for antimicrobial resistance [7]. In the quest for sustainable alternatives, quercetin prompted interest since this molecule showed excellent assets in an intestinal porcine epithelial cell (IPEC-J2) line [8]. Among the six antioxidants tested here, quercetin was most effective in reducing ROS and supporting barrier function. Growing evidence further indicates that quercetin is 
also a potent modulator of the glutathione (GSH) redox system. Glutathione transferase (GST) and glutamate-cysteine ligase (GCL) are the two principal enzymes upregulated by quercetin through interference with redox signaling mechanisms [9-13]. While GST enables the conjugation of GSH to proteins and xenobiotics, GCL catalyzes the first and rate-limiting step in the synthesis of GSH. The effects on other GSH-related enzymes, such as glutathione peroxidase (GPx) and glutathione reductase (GR), which respectively catalyze the oxidation of GSH and reduction of glutathione disulphide (GSSG), are not well documented. This though could be important since redox mechanisms are involved in tight junction regulation [14-16] and cell cycling from proliferation to apoptosis [17,18], and redox disturbance occurs during the weaning transition of piglets $[19,20]$.

Research on the beneficial effects of quercetin in pigs is however limited [21,22] compared to the considerable amount of data generated in rodent models for experimentally induced colitis. In these experiments, quercetin and its naturally occurring glycosides quercetrin and rutin all demonstrated a remarkable potential to attenuate colonic mucosal damage [23-34]. When targeting the small intestine, quercetin could be the preferential source, as the beneficial effects are primarily ascribed to quercetin and not its metabolites [35]. Besides, its glycosides need an additional step of hydrolysis, either by lactase-phlorizin hydrolase at the brush border surface, by the intestinal microbiota, or intracellularly after active transport of monoglycosides $[23,36,37]$. This might not favor its functionality at the level of the small intestine.

After oral ingestion, quercetin is easily absorbed and further metabolized by the small intestine. Using an in situ perfusion model of the rat jejunum plus ileum, Crespy et al. (1999) found that two-thirds of the quercetin disappeared from the lumen. A high proportion of quercetin was also found to be re-excreted into the lumen as conjugated derivates [38]. Conjugation of orally administered quercetin with glucuronic and sulfuric acid appears to preferentially occur in the intestinal wall of pigs, which further explains the low apparent bioavailability of free, unchanged quercetin $[37,39]$. A recent study in rats demonstrated that the intestinal epithelium is the major site of glucuronidation, while the liver rather promotes sulfation and methylation of quercetin. Quercetin can be easily methylated by catechol-O-methyl transferase. However, this rate appears to be low in the pig $[30,37,40]$. The resulting glucurono- and sulfo-conjugated metabolites of quercetin and its methylated metabolites isorhamnetin and tamarixetin are the main circulating forms in plasma [37,40]. Importantly, glucurono-, but not sulfo-conjugates, can be hydrolyzed at the vascular level, yielding the aglycone, which can accumulate in tissues [36]. Accumulation is considered to be limited in pigs, as the tissue distribution of quercetin and its metabolites is not different between a single treatment and long-term dietary intake of quercetin [40]. Predominantly organs involved in the metabolism and excretion of quercetin, including the liver, small intestine and kidney, were observed to hold higher flavonol concentrations than plasma. Yet colon tissue contained three times the amount of jejunal tissue, and this almost exclusively as the quercetin aglycone [40]. The colon thus remains the main site for quercetin accumulation, although the small intestine extensively absorbs and metabolizes quercetin. As the concentration of the molecule dictates its potential effect, it thus remains unclear whether the small intestine would benefit from quercetin supplementation. Finally, it should be emphasized that the pharmacokinetics of quercetin and its glycosides is species-dependent $[40,41]$. In this study, we therefore aimed to elaborate on the effects of quercetin on the small intestinal mucosa in piglets during the weaning transition. We investigated the small intestinal functionality and the GSH redox at $\mathrm{d} 5$ and $\mathrm{d} 14$ post-weaning, respectively allowing to assess the prevention and the recovery of intestinal damage upon weaning.

\section{Materials and Methods}

\subsection{Experimental Animals and Feeds}

The experiment was carried out according to the guidelines of the Ethical Committee of the Faculty of Veterinary Sciences, Ghent University (Ghent, Belgium) for the humane care and use of animals in research. For this experiment, 224 piglets (Piétrain $\times$ Topigs hybrid) were selected at weaning from 
32 litters at one farm. 119 Barrows and 106 gilts $(4.0-8.5 \mathrm{~kg})$ were weaned at 21 days of age. Selected piglets were inspected for health prior to transport to the trial facilities. Piglets were allocated to 32 pens, each holding seven piglets per pen, according to the protocol described below. Pens had a surface area of $2.10 \mathrm{~m}^{2} /$ pen, and were equipped with full slatted floors, a single-sided dry feeder $(60 \mathrm{~cm}$ wide) and one bowl drinker. From d0 to d14 post-weaning, piglets were fed the four different experimental weaner diets, varying in the dose of quercetin. The starter diet was then offered from d14 to d42 post-weaning and was identical for all treatments. Diets were barley-, wheat- and soy-based meals, formulated to meet or exceed recommendations by the Dutch Centraal Veevoederbureau (1997) [42]. The weaner and starter diets contained basal levels of vitamin E (54 IE/kg), butylated hydroxytoluene $(75 \mathrm{mg} / \mathrm{kg})$ and ethoxyquin $(38 \mathrm{mg} / \mathrm{kg})$, but no in-feed antibiotics or pharmacological doses of zinc oxide (supplemental $\mathrm{Zn}^{2+}: 100 \mathrm{mg} / \mathrm{kg}$ ). More details on the ingredient and nutrient composition can be found in Table 1.

Table 1. Ingredient and calculated nutrient composition of the weaner and starter diet, fed to piglets from $\mathrm{d} 0-14$ and d14-42 post-weaning, respectively.

\begin{tabular}{|c|c|c|}
\hline Ingredient Composition [\%] & Weaner Diet & Starter Diet \\
\hline Barley & 25.00 & 35.00 \\
\hline Wheat & 23.38 & 15.00 \\
\hline Toasted soybeans & 19.97 & 4.00 \\
\hline Corn & 15.00 & 17.31 \\
\hline Sweet whey powder & 5.00 & \\
\hline Sugar beet pulp & 2.00 & 2.00 \\
\hline Lard & & 2.00 \\
\hline Lactic acid (52\%) & 1.92 & \\
\hline Soybean meal ( $49 \%$ crude protein) & 1.53 & 19.34 \\
\hline Lactose & 1.27 & \\
\hline Potato protein & 1.22 & \\
\hline Monocalciumphosphate & 0.79 & 1.15 \\
\hline Limestone (fine) $38 \% \mathrm{Ca}$ & 0.58 & 1.00 \\
\hline Soybean oil & & 0.73 \\
\hline Salt & 0.28 & 0.45 \\
\hline L-lysine $\mathrm{HCl}$ & 0.48 & 0.45 \\
\hline DL-methionine & 0.25 & 0.21 \\
\hline L-threonine & 0.22 & 0.19 \\
\hline L-valine & 0.22 & 0.12 \\
\hline L-tryptophan & 0.07 & 0.05 \\
\hline Vitamin and mineral premix ${ }^{1}$ & 1.00 & 1.00 \\
\hline \multicolumn{3}{|l|}{ Calculated Nutrient Levels } \\
\hline Net energy ${ }^{2}[\mathrm{MJ} / \mathrm{kg}]$ & 10.1 & 9.8 \\
\hline Crude protein $[\mathrm{g} / \mathrm{kg}]$ & 169 & 180 \\
\hline Ether extract $[\mathrm{g} / \mathrm{kg}]$ & 54.9 & 53.0 \\
\hline Digestible lysine $^{2}$ [g/kg] & 11.5 & 11.0 \\
\hline 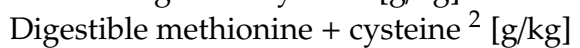 & 6.9 & 6.6 \\
\hline Digestible threonine ${ }^{2}[\mathrm{~g} / \mathrm{kg}]$ & 7.1 & 6.8 \\
\hline Digestible tryptophan ${ }^{2}[\mathrm{~g} / \mathrm{kg}]$ & 2.3 & 2.2 \\
\hline Digestible valine ${ }^{2}[\mathrm{~g} / \mathrm{kg}]$ & 8.1 & 7.7 \\
\hline
\end{tabular}

\footnotetext{
${ }^{1}$ The mineral and vitamin premix supplied as the following (per kg diet): Vitamin A, 10,000 IU; Vitamin D3, 2000 IU; Vitamin E; 54 IE Vitamin K3, 1 mg; Vitamin B1, 1.2 mg; Vitamin B2, 3.7 mg; Vitamin B3, 12 mg; Vitamin B5, 25 mg; Vitamin B6, $2 \mathrm{mg}$; Vitamin B12, $0.030 \mathrm{mg}$; Biotin, $0.2 \mathrm{mg}$; Niacine, $20 \mathrm{mg}$; Folic acid, $0.8 \mathrm{mg}$; $\mathrm{Fe}^{2+}, 100 \mathrm{mg} \mathrm{Zn}{ }^{2+}$, $100 \mathrm{mg}$; $\mathrm{Cu}^{2+}, 15 \mathrm{mg}$; $\mathrm{Mn}^{2+}, 80 \mathrm{mg}$; $\mathrm{Se}^{6+}, 0.3 \mathrm{mg}$; I, $1 \mathrm{mg}$, BHT, $75 \mathrm{mg} / \mathrm{kg}$; ethoxyquin, $37.7 \mathrm{mg} / \mathrm{kg}$; choline, $500 \mathrm{mg}$; phytase, 500 FTU. ${ }^{2}$ Net energy for pigs CVB (1997), Centraal Veevoederbureau, Lelystad, The Nederlands [42].
}

\subsection{Experimental Design and Measurements}

The experiment included four dietary treatments, i.e., the weaner diet (d0-14 post-weaning) contained 0 (QUE0), 100 (QUE100), 300 (QUE300) or 900 (QUE900) mg quercetin per kg diet. The diets 
were prepared by first preparing one batch of basal weaner diet, dividing this in four equal batches, and mixing the appropriate amount of quercetin into the diet. Quercetin (CAS 117-39-5) was obtained from Sigma Aldrich (Overijse, Belgium) as a $\geq 95 \%$ grade powder. Treatments were replicated in eight pens with seven animals per pen. First, piglets were allocated to the pens in order to stratify for mean body weight and litter origin. Here, eight littermate piglets were divided over eight neighboring pens, and seven different litters were used to reach a total of seven piglets per pen. This process was repeated four times, resulting in a randomized block design where each treatment was randomly assigned to two pens per block. At minimum, two out of seven piglets per pen represented each gender. Piglets were weighed individually at d0, d5, d14, d28, and d42 post-weaning. Feed intake was registered at the pen level by weighing feeders and residual feed. Average daily gain (ADG), average daily feed intake (ADFI), and feed conversion ratio (FCR) were calculated for following intervals; $\mathrm{d} 0-5$, $\mathrm{d} 5-14$, d14-28, d28-42, and d0-42 post-weaning.

An ordinal scoring system was used by a trained individual to daily score the fecal consistency of each pen throughout the $14 \mathrm{~d}$ post-weaning period, and included three categories: $1=$ hard or slightly moist feces, clearly formed, normal; 2 = moist or soft feces, but still with a definite form, sticky; and 3 = watery or liquid feces, unformed, diarrhea. Diarrhea incidence was simultaneously assessed by counting pigs with a fecal consistency score of 3 , including clear signs of diarrhea: filthy, wet backside and tail, dehydrated, loss of condition, and irritation of the skin around the anus. Antibiotic treatments were registered and were limited to individual intramuscular injections.

\subsection{Sample Collection}

Both at $\mathrm{d} 5$ and $\mathrm{d} 14$, one piglet per pen was euthanized and sampled. Here, the animal having the body weight closest to the average body weight of the pen at that time was selected, irrespective of their gender. No fasting period was included. Animals were anaesthetized by electrical stunning and during exsanguination, blood was collected in heparinized tubes containing $200 \mu \mathrm{L}$ bathophenanthroline disulfonic acid and K3-EDTA tubes. After immediate centrifugation $(3000 \times g, 10 \mathrm{~min})$, K3-EDTA plasma was harvested and stored at $-20^{\circ} \mathrm{C}$ for the analysis of malondialdehyde (MDA), GPx, GR, GST, and GCL, while heparinized plasma was discarded, and erythrocytes were lysed with metaphosphoric acid and intense vortexing. Samples were then centrifuged ( $3000 \times g, 10 \mathrm{~min})$, and $0.5 \mathrm{~mL}$ of the resulting acid extract was supplemented with $\gamma$-glutamyl-glutamate, snap frozen and stored at $-80{ }^{\circ} \mathrm{C}$. Meanwhile, a first $10 \mathrm{~cm}$ section was obtained at 75\% (distal jejunum) of the total small intestinal length and was used in the Ussing chamber assay to determine the macromolecular permeability according to the principles describe below. A second section of intestinal tissue $(20 \mathrm{~cm})$, both at $5 \%$ (duodenum) and 75\%, was harvested for its mucosa by scraping the mucosal surface with a glass slide. A first mucosal subsample was homogenized in ice cold perchloric acid (1:10 m:v; $1.16 \mathrm{M})$ with a Braun Potter homogenizer $(1000 \mathrm{rpm}, 30 \mathrm{~s})$. Homogenates were centrifuged $(10,000 \times g, 15 \mathrm{~min}$, $4{ }^{\circ} \mathrm{C}$ ), after which an aliquot was supplemented with $\gamma$-glutamyl-glutamate, snap frozen in liquid nitrogen and stored at $-80^{\circ} \mathrm{C}$. These extracts were used for the quantification of GSH and GSSG. At the same time, a second mucosal subsample was homogenized in a $1 \%$ triton-X-100 phosphate-buffer ( $\mathrm{pH} 7.0,50 \mathrm{mM}, 1: 10 \mathrm{m:v})$, and was centrifuged $\left(10,000 \times g, 15 \mathrm{~min}, 4^{\circ} \mathrm{C}\right)$. The supernatants were snap frozen and stored at $-20^{\circ} \mathrm{C}$ pending the analysis of the total protein content, MDA, GPx, GR, GST, and GCL. A third mucosal subsample was snap frozen and stored at $-80^{\circ} \mathrm{C}$ awaiting the analysis of protein abundance. A last section of intestinal tissue $(5 \mathrm{~cm})$ at both intestinal sites was placed in $4 \%$ paraformaldehyde solution ( $\mathrm{pH}$ 7.4) for two hours, followed by rinsing with phosphate-buffered saline and further processed according to standard procedures for histomorphology. Finally, also the liver was excised and perchloric acid and phosphate-buffered extracts were made and stored identical to the procedures for small intestinal mucosa. 


\subsection{Laboratory Analysis}

The GPx activity assay, as described by Hernandez et al. (2004) [43], was based on measuring the consumption of NADPH at $340 \mathrm{~nm}$, in a reaction mixture containing NADPH, GR and GSH. One unit of GPx activity was equivalent to one $\mu \mathrm{mol} \mathrm{NADP}+$ from NADPH per minute at $\mathrm{pH} 8.0$ and $25^{\circ} \mathrm{C}$. The activity of GR was determined according to the method of Carlberg and Mannervik (1985) [44]. This was based on the reduction of GSSG by NADPH in the presence of GR and monitoring the disappearance of NADPH at $340 \mathrm{~nm}$. One unit of GR caused the oxidation of one $\mu$ mole of NADPH at $25{ }^{\circ} \mathrm{C}(\mathrm{pH}=7.5)$. The GST activity was determined by measuring the increase in absorbance at $340 \mathrm{~nm}$, associated with the conjugation of GSH with 1-chloro-2,4-dinitrobenzene (CDNB) catalyzed by GST [45]. One unit of GST conjugated one $\mu \mathrm{mol}$ of CDNB with GSH per minute at $25^{\circ} \mathrm{C}(\mathrm{pH}=6.5)$. The activity of GCL was determined according to the method of White et al. (2003), based on the reaction of naphthalene-2,3-dicarboxialdehyde (NDA) with the $\gamma$-glutamylcysteine $(\gamma$-GC) produced in a medium containing ATP, glutamic acid, cysteine and sample (1725) [46]. Fluorescence intensity was measured at $472 \mathrm{~nm}$ excitation and $528 \mathrm{~nm}$ emission. One unit of GCL was defined as one nmol of NDA- $\gamma$-GC formed per minute at $25^{\circ} \mathrm{C}(\mathrm{pH}=7.5)$. The thiobarbituric acid reactive substances method was employed to quantify MDA as a marker for lipid peroxidation [47]. Finally, a bicinchonic acid assay was used to quantify the protein content in phosphate-buffered mucosal and hepatic extracts [48].

The concentrations of GSH and GSSG were determined by the methodology of Yoshida et al. (1996) [49], relative to $\gamma$-glutamyl-glutamate as internal standard and to GSH and GSSG external standard solutions. The analytical procedure was identical as in earlier research [50,51]. In brief, in involves the quantification of N-(2,4-dinitrophenyl) derivates by reversed-phase HPLC and with UV absorption measurement at $365 \mathrm{~nm}$. The GSH/GSSG $\mathrm{E}_{\mathrm{h}}$ values (in $\mathrm{mV}$ ) were calculated by using the appropriate forms of the Nernst equation, at $\mathrm{pH} 7.4$ and $37^{\circ} \mathrm{C}$, whereby concentrations of GSH and GSSG were expressed in molarity [52]:

$$
G S H / G S S G E_{h}=-264-\frac{61.5}{2} \times \log _{10}\left(\frac{G S H^{2}}{G S S G}\right)[m V]
$$

The mucosal permeability for 4-kDa fluorescein isothiocyanate dextran (FD4; Sigma-Aldrich, Overijse, Belgium) was assessed in an Ussing chamber setup. Three distal jejunal segments per pig were striped from its serosal layers and mounted into inserts with an opening area of $1.07 \mathrm{~cm}^{2}$ within $15 \mathrm{~min}$ post-mortem. Further procedures were identical as earlier described [53]. Samples in the acceptor compartment were taken at 20-min intervals between $40 \mathrm{~min}$ and $100 \mathrm{~min}$ after mounting the segment, and the fluorescent signal was captured using excitation filter at $\lambda=494 \mathrm{~nm}$ and emission filter at $\lambda=521 \mathrm{~nm}$. The change in concentration over time (dc/dt) was calculated from the slope of concentration-time curve $(\mu \mathrm{g} / \mathrm{mL}$ per s). The apparent permeability coefficient (Papp) was then calculated following the equation described by Neirinckx et al. (2011) [53].

The standard histomorphology procedures included dehydration and paraffin embedding, whereafter $5 \mu \mathrm{m}$ transverse sections were mounted on slides and stained with hematoxylin-eosin. Villus height, villus width and crypt depth were measured in 50 well-oriented villi and adjacent crypts using an Olympus BX61 microscope and image analysis software (analySIS Pro, Olympus, Aartselaar, Belgium), in at least 10 sections per tissue sample.

The protein level of occludin, caspase- 3 and proliferating cell nuclear antigen (PCNA) were assessed using commercially available enzyme-linked immunosorbent assays (ELISA) (Cloud-Clone Corporation ${ }^{\circledR}$, Houston, TX, USA), respectively with the product code SEC228Hu, SEA626Hu, SEA591Hu. Therefore, mucosal samples were crushed, dissolved in phosphate-buffered saline ( $\mathrm{pH} 7.4$, $10 \mathrm{mM}$ ), sonicated $\left(6\right.$ times $\left.5 \mathrm{~min}, 4^{\circ} \mathrm{C}\right)$, kept on ice for $30 \mathrm{~min}$, and centrifuged $\left(10,000 \times g, 2 \mathrm{~min}, 4^{\circ} \mathrm{C}\right)$. The supernatant was diluted to a total protein concentration of $10 \mathrm{ng} / \mu \mathrm{L}$. Samples were then processed on a sandwich ELISA plate and the experiment was performed according to the manufacturer's 
instructions. Absorbance was measured at $450 \mathrm{~nm}$ and $25^{\circ} \mathrm{C}$, and values of protein abundance were expressed as fmol per mg protein.

\subsection{Statistics}

Performance and analytical data were subjected to a general linear model module in IBM SPSS Statistics version 24.0 (SPSS Inc., Chicago, IL, USA). First, data were checked for violations on the normality and homoscedasticity assumptions. The individual piglet was considered as the experimental unit for analytical variables $(n=8)$, and the model contained dietary treatment (QUE), day post-weaning $(\mathrm{DAY})$ and their interaction $(\mathrm{DAY} \times \mathrm{QUE})$ as fixed effects. Performance data at the pen level $(n=8)$ were analyzed per time point, and the model contained the fixed effect of dietary treatment and the random effect of block. Data are presented as least squares means with the standard error of the mean (SEM) in tables, or with the standard deviation (SD) in figures. Differences were considered significant at $p \leq 0.05$, and statistical tendencies were assumed when $0.10>p>0.05$. Tukey's multiple comparison test was applied to discriminate the dietary treatments.

Principal component analysis (PCA) was used as a dimension reduction technique, to evaluate if treatments groups had altered overall GSH redox status and gut functionality. Data were standardized, i.e., for each observation, the value was subtracted with the grand mean and divided by the standard deviation. A first PCA was conducted with the data from 23 variables on the GSH redox status at d5 and d14 post-weaning, being the GSH and GSSG concentrations and the activities of GSH-related enzymes in erythrocytes or plasma, duodenal mucosa, distal jejunal mucosa, and liver. The GSH/GSSG $\mathrm{E}_{\mathrm{h}}$ was not included since this variable is computed from the GSH and GSSG concentrations and resulted in multicollinearity. The plasma GR activity was not included since no detectable amounts of activity could be monitored. MDA concentrations were not included in order to attain a subject-to-variable ratio of approximately three to one. An initial PCA gave rise to seven principal components with an eigenvalue higher than one. The first two principal components, with initial eigenvalues of 4.3 and 3.2, were retained for a final PCA. A second PCA analysis contained all variables on histomorphology, FD4 flux and PCNA, caspase-3 and occludin protein abundance. The subject-to-variable ratio was approximately six to one. The first two principal components, with initial eigenvalues of 3.1 and 2.1, were retained from a list of three components with an eigenvalue higher than one. For both PCA's, the Kaiser-Meyer-Olkin statistic of sampling adequacy was $\geq 0.6$, and Bartlett's test of sphericity indicated multivariate normal distribution with zero covariance $(p<0.001)$. Varimax rotation with Kaiser normalization was applied to ensured maximal sum of the variances of the squared loadings matrix. Piglets received component scores for the two principal components by using the least squares regression approach. An identical statistical model was used as for the analytical variables, to test the effect DAY, QUE and DAY $\times$ QUE on the scorings of those final components.

\section{Results}

\subsection{Animal Performance}

During the first 14 days of the experiment, when the four different experimental diets were fed, no significant differences were found on animal performance (Table 2). Piglets fed the QUE300 diet lost weight until d5 post-weaning, whereas other treatment groups displayed a slightly positive ADG in this period $(p>0.05)$. The ADFI at $\mathrm{d} 0-5$ and $\mathrm{d} 5-14$ post-weaning was also not found to differ between treatments, indicating that piglets had no preference nor aversion towards quercetin up to a dose of $900 \mathrm{mg} / \mathrm{kg}$ diet. Similarly, FCR was not affected by dietary treatment in this phase. At d14 post-weaning, piglets were switched from the weaner diet to the starter diet, which did not contain quercetin and thus was identical for all treatments. Remarkably, treatment effects were observed in this phase of the experiment. The BW at $\mathrm{d} 28$ and $\mathrm{d} 42$ post-weaning were significantly increased with respectively 0.96 and $1.39 \mathrm{~kg}$ more for treatment QUE900, as compared to QUE300. This was reflected in a significantly higher ADG for treatment QUE900 compared to QUE300 when considering the 
entire experiment (d0-42 post-weaning). Also, feed intake was influenced by the dietary treatment. From d28 to d42 post-weaning, the ADFI was increased with 9\% in QUE900 when compared to the control (QUE0) $(p=0.046)$. Lastly, treatment did not affect the FCR at any given time, indicating that the increased growth in QUE900 was the result of a higher feed intake, rather than a more efficient feed utilization.

Table 2. The effect of quercetin at doses of 0,100, 300, or $900 \mathrm{mg} / \mathrm{kg}$ diet (QUE) fed during the first 14 days post-weaning on animal performance of piglets from $\mathrm{d} 0$ to $\mathrm{d} 42$ post-weaning $(n=8)$.

\begin{tabular}{|c|c|c|c|c|c|c|}
\hline & \multicolumn{4}{|c|}{ QUE } & \multirow{2}{*}{ SEM } & \multirow{2}{*}{$p$-Value } \\
\hline & $\mathbf{0}$ & 100 & 300 & 900 & & \\
\hline \multicolumn{7}{|c|}{ Body weight (BW) [kg] } \\
\hline $\mathrm{d} 0$ & 5.88 & 5.88 & 5.88 & 5.88 & 0.03 & 0.956 \\
\hline $\mathrm{d} 5$ & 6.00 & 5.99 & 5.82 & 5.96 & 0.04 & 0.174 \\
\hline $\mathrm{d} 14$ & 6.87 & 6.73 & 6.54 & 7.06 & 0.11 & 0.201 \\
\hline $\mathrm{d} 28$ & $11.63^{\mathrm{ab}}$ & $11.46^{a b}$ & $11.22^{\mathrm{a}}$ & $12.18^{\mathrm{b}}$ & 0.15 & 0.039 \\
\hline $\mathrm{d} 42$ & $18.06^{\mathrm{ab}}$ & $17.92^{a b}$ & $17.70^{\mathrm{a}}$ & $19.09^{b}$ & 0.21 & 0.029 \\
\hline \multicolumn{7}{|c|}{ Average daily gain (ADG) $[\mathrm{g} / \mathrm{d}]$} \\
\hline $\mathrm{d} 0-5$ & 24 & 19 & -7 & 16 & 7 & 0.256 \\
\hline d5-14 & 91 & 81 & 80 & 113 & 10 & 0.376 \\
\hline d14-28 & 310 & 310 & 306 & 337 & 5 & 0.056 \\
\hline $\mathrm{d} 28-42$ & 478 & 482 & 487 & 523 & 8 & 0.067 \\
\hline $\mathrm{d} 0-42$ & $286^{a b}$ & $284^{\mathrm{ab}}$ & $282^{a}$ & $313^{b}$ & 5 & 0.030 \\
\hline \multicolumn{7}{|c|}{ Average daily feed intake (ADFI) [g/d] } \\
\hline $\mathrm{d} 0-5$ & 71 & 67 & 52 & 63 & 5 & 0.348 \\
\hline d5-14 & 178 & 168 & 156 & 197 & 9 & 0.183 \\
\hline d14-28 & 436 & 432 & 421 & 469 & 9 & 0.120 \\
\hline $\mathrm{d} 28-42$ & $740^{a}$ & $747^{a b}$ & $759 \mathrm{ab}$ & $807^{b}$ & 11 & 0.046 \\
\hline $\mathrm{d} 0-42$ & 396 & 395 & 389 & 429 & 7 & 0.070 \\
\hline \multicolumn{7}{|c|}{ Feed conversion ratio (FCR) [ADG/ADFI] } \\
\hline $\mathrm{d} 0-5$ & 0.308 & 0.206 & -0.912 & 0.237 & 0.333 & 0.346 \\
\hline d5-14 & 0.489 & 0.473 & 0.276 & 0.575 & 0.102 & 0.598 \\
\hline d14-28 & 0.712 & 0.718 & 0.733 & 0.721 & 0.010 & 0.848 \\
\hline d28-42 & 0.646 & 0.644 & 0.642 & 0.648 & 0.004 & 0.892 \\
\hline $\mathrm{d} 0-42$ & 0.722 & 0.720 & 0.728 & 0.734 & 0.006 & 0.736 \\
\hline
\end{tabular}

${ }^{\mathrm{a}, \mathrm{b}}$ Within a row, least square means without a common superscript letter differ significantly $(p \leq 0.05)$.

Diarrhea incidence and watery feces were most frequently observed between $\mathrm{d} 5$ and $\mathrm{d} 12$ post-weaning (data not shown). The average fecal consistency score was unaffected by dietary treatment $(p>0.05)$, and the overall score amounted to 1.80 on a scale from 1 (firm) to 3 (watery). Incidence of diarrhea was moderate, as on average $7.2 \%, 7.0 \%, 6.7 \%$ and $2.9 \%(p>0.05)$ of the piglets showed clear visual indications of diarrhea, respectively for treatment QUE0, QUE100, QUE300 and QUE900. In total, four animals had to be removed from the study due to outlier performance, i.e., one animal from treatment QUE0, two from QUE100, and one from QUE900. These animals showed a reduced vitality, failed to thrive for several days, and did not respond to treatment with meloxicam. In total, only five antibiotic treatments with enrofloxacine were administered to piglets showing signs of arthritis, gastrointestinal or respiratory infections. This was unrelated to the dietary treatment. Furthermore, two piglets unexpectedly died during the experiment. One animal from treatment QUE100 was found dead on $\mathrm{d} 2$ post-weaning, and one animal from treatment QUE0 was found dead at $\mathrm{d} 29$ post-weaning. In both cases of sudden death, these animals were not found to be anorexic or lethargic. No post-mortem autopsy was executed. 


\subsection{Lipid Peroxidation in Different Tissues}

Malondialdehyde was measured in different tissues as a marker for lipid peroxidation (Table 3). The results indicate that dietary quercetin did not influence the MDA concentrations in tissues (QUE: $p>0.05$; DAY $\times$ QUE: $p>0.05$ ). However, MDA levels were significantly affected by DAY in all measured tissues $(p \leq 0.05)$. Plasma levels were $17 \%$ higher on $\mathrm{d} 5$ versus d 14 post-weaning, whereas duodenal and distal jejunal MDA was respectively $29 \%$ and $16 \%$ higher on d5 post-weaning. Finally, also hepatic MDA levels were higher at $\mathrm{d} 5$ when compared to $\mathrm{d} 14$ post-weaning $(+25 \%)$.

Table 3. The effect of quercetin at a dose of either $0,100,300$, or $900 \mathrm{mg} / \mathrm{kg}$ diet (QUE) fed during the first $14 \mathrm{~d}$ post-weaning on the malondialdehyde (MDA) concentration in different tissues of piglets at $\mathrm{d} 5$ and $\mathrm{d} 14$ post-weaning (DAY) $(n=8)$.

\begin{tabular}{|c|c|c|c|c|c|c|c|c|c|c|c|c|}
\hline \multirow{2}{*}{$\begin{array}{l}\text { DAY } \\
\text { QUE }\end{array}$} & \multicolumn{4}{|c|}{5} & \multicolumn{4}{|c|}{14} & \multirow{2}{*}{ SEM } & \multicolumn{3}{|c|}{$p$-Value } \\
\hline & 0 & 100 & 300 & 900 & 0 & 100 & 300 & 900 & & DAY & QUE & DAY $\times$ QUE \\
\hline \multicolumn{13}{|c|}{ MDA [nmol/g prot.] } \\
\hline Plasma $^{1}$ & 9.01 & 8.46 & 8.62 & 7.94 & 7.00 & 7.55 & 7.28 & 7.38 & 0.12 & $<0.001$ & 0.694 & 0.202 \\
\hline Duodenal mucosa & 361 & 453 & 398 & 383 & 310 & 347 & 304 & 284 & 12 & $<0.001$ & 0.124 & 0.909 \\
\hline Distal jejunal mucosa & 483 & 556 & 491 & 519 & 472 & 403 & 472 & 419 & 17 & 0.042 & 0.994 & 0.398 \\
\hline Liver & 1380 & 1057 & 1155 & 1149 & 875 & 974 & 982 & 948 & 32 & $<0.001$ & 0.663 & 0.125 \\
\hline
\end{tabular}

${ }^{1}$ Expressed in $\mathrm{nmol} / \mathrm{mL}$.

\subsection{Responses of the Glutathione Redox System in Different Tissues}

\subsubsection{The Glutathione Redox System in Blood}

Including quercetin in the diet did not impact on the glutathione redox system in erythrocytes or plasma (Table 4, Figure 1). Glutathione-related enzymes were not affected by QUE and DAY $\times$ QUE. The GSH levels in erythrocytes tended to be affected by QUE, with lower levels in treatment QUE300 $(p=0.077)$. Moreover, the GSH redox system responded differently at $\mathrm{d} 5$ versus $\mathrm{d} 14$ post-weaning irrespective of dietary treatment $(p \leq 0.05)$. Here, d5 post-weaning was characterized by $18 \%$ lower GSH levels, $18 \%$ increased GSSG levels, and consequently a more oxidized erythrocyte GSH/GSSG Eh $(+7 \mathrm{mV})$. This was joined by a $26 \%$ higher GST activity and a $48 \%$ lower GCL activity in plasma on d5 post-weaning. Plasma GPx activity was also significantly lower $(-19 \%)$ on d5 than d14 post-weaning. We could not confirm that this was combined with altered activity of GR, as our current method yielded values below the detection limit.

Table 4. Significance levels for treatment effects on the glutathione redox system in blood of piglets at d5 and d14post-weaning (DAY), fed a diet containing 0, 100, 300, or $900 \mathrm{mg}$ quercetin/kg diet (QUE) during the first $14 \mathrm{~d}$ post-weaning $(n=8)$.

\begin{tabular}{ccccccc}
\hline$p$-Value & GPx & GST & GCL & GSH & GSSG & GSH/GSSG E \\
\hline DAY & 0.003 & 0.009 & $<0.001$ & 0.001 & 0.039 & $<0.001$ \\
QUE & 0.776 & 0.741 & 0.974 & 0.077 & 0.925 & 0.115 \\
DAY $\times$ QUE & 0.076 & 0.146 & 0.936 & 0.912 & 0.221 & 0.624 \\
\hline
\end{tabular}



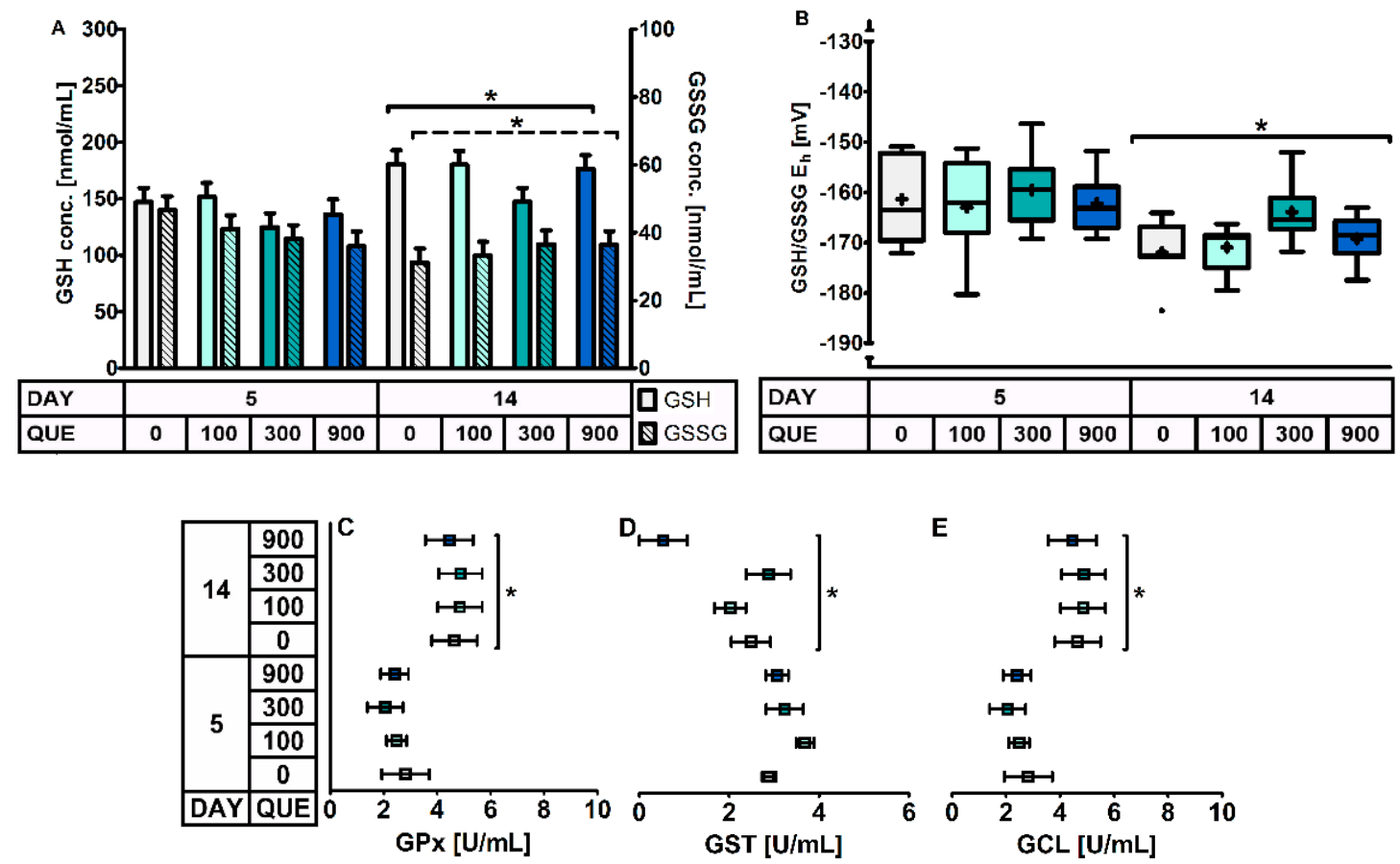

Figure 1. The glutathione redox system in blood of piglets at $\mathrm{d} 5$ and d14 post-weaning (DAY), fed a diet containing 0,100,300, or $900 \mathrm{mg}$ quercetin/kg diet (QUE) during the first $14 \mathrm{~d}$ post-weaning. Results are presented as least squares means with SD. Significance levels of main effects and interaction terms are presented in Table 4: (A) glutathione (GSH) and glutathione disulphide (GSSG) concentrations in erythrocytes; (B) Glutathione redox status (GSH/GSSG $E_{h}$ ) in erythrocytes; (C) Glutathione peroxidase (GPx) activity in plasma; (D) Glutathione transferase (GST) activity in plasma; (E) Glutamate-cysteine ligase (GCL) activity in plasma. * Represents the effect of DAY across other factors $(p \leq 0.05)$.

\subsubsection{The Small Intestinal Mucosal Glutathione Redox System}

The small intestinal GSH redox system was quantified both in the duodenal and distal jejunal mucosa. In the duodenal mucosa (Table 5, Figure 2), no effect of QUE nor DAY $\times$ QUE on the different components of the GSH redox system were observed $(p>0.05)$. However, similar as in plasma, the day post-weaning had an effect. The GSH/GSSG $\mathrm{E}_{\mathrm{h}}$ was $14 \mathrm{mV}$ higher on $\mathrm{d} 5$ versus d14 post-weaning. This was accompanied by a $40 \%$ lower GSH level $(p<0.001)$. GSSG concentrations did not to differ between $\mathrm{d} 5$ and $\mathrm{d} 14$ post-weaning. This drop in duodenal GSH was not associated with an altered GSH synthesis rate, as the GCL activity was similar at $\mathrm{d} 5$ and d14 post-weaning $(p>0.05)$. Instead, the drop in duodenal GSH was rather instigated by a $24 \%$ higher GST activity on d5 post-weaning. Piglets at $\mathrm{d} 5$ were also characterized by a higher GSH cycling redox activity, as both GPx $(+22 \%)$ and GR (+22\%) were significantly higher as compared to d14 post-weaning.

Table 5. Significance levels for treatment effects on the glutathione redox system in the duodenal mucosa of piglets at d5 and d14post-weaning (DAY), fed a diet containing either 0, 100, 300, or $900 \mathrm{mg}$ quercetin/kg diet (QUE) during the first $14 \mathrm{~d}$ post-weaning $(n=8)$.

\begin{tabular}{cccccccc}
\hline$p$-Value & GPx & GR & GST & GCL & GSH & GSSG & GSH/GSSG E $_{\mathbf{h}}$ \\
\hline DAY & 0.044 & 0.002 & 0.021 & 0.200 & $<0.001$ & 0.542 & $<0.001$ \\
QUE & 0.787 & 0.346 & 0.837 & 0.650 & 0.614 & 0.664 & 0.682 \\
DAY $\times$ QUE & 0.355 & 0.750 & 0.624 & 0.288 & 0.891 & 0.939 & 0.742 \\
\hline
\end{tabular}



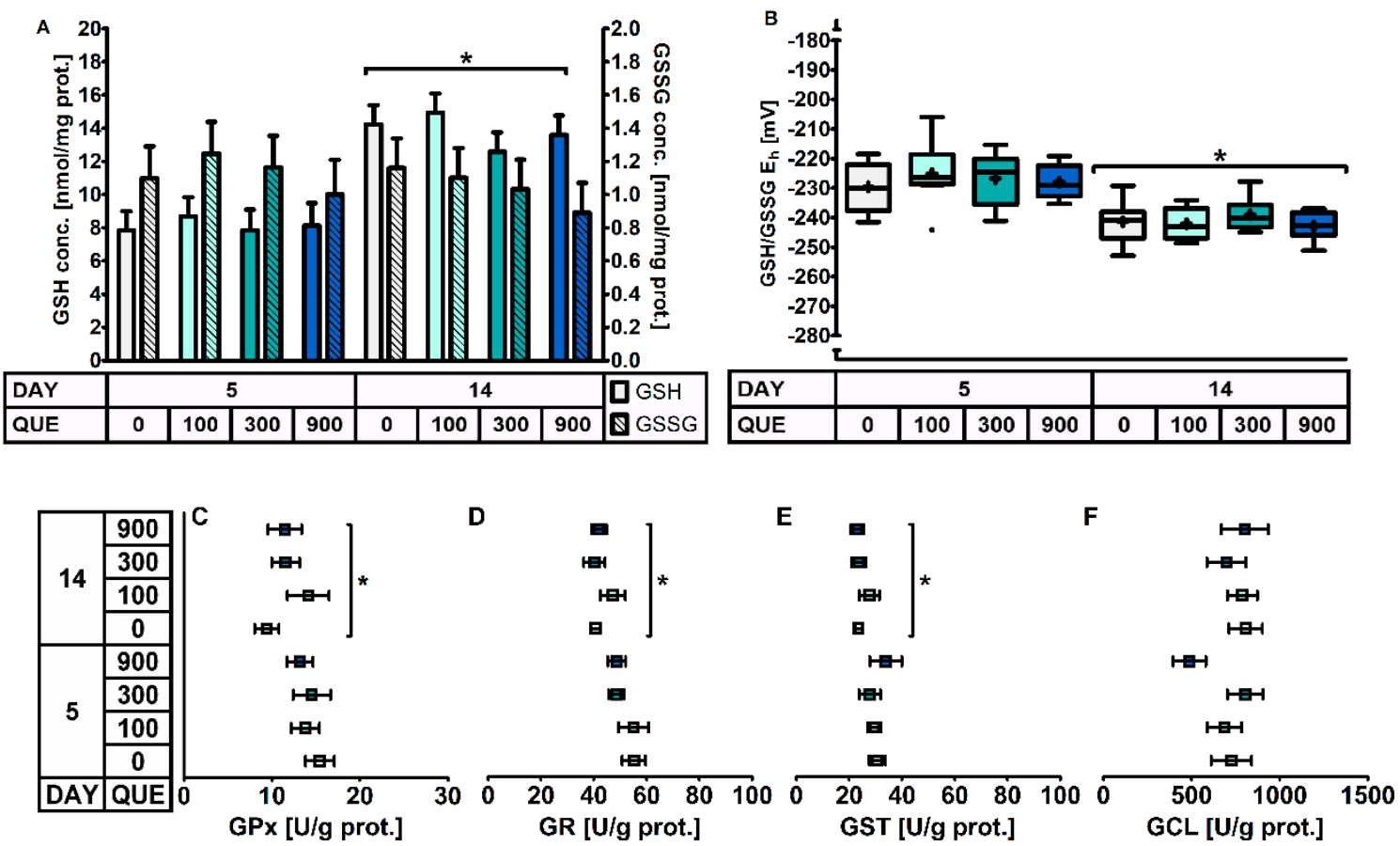

Figure 2. The glutathione redox system in the duodenal mucosa of piglets at $\mathrm{d} 5$ and $\mathrm{d} 14$ post-weaning (DAY), fed a diet containing 0, 100, 300, or $900 \mathrm{mg}$ quercetin/ $\mathrm{kg}$ diet (QUE) during the first 14d post-weaning. Results are presented as least squares means with SD. Significance levels of main effects and interaction terms are presented in Table 5: (A) glutathione (GSH) and glutathione disulphide (GSSG) concentrations; (B) Glutathione redox status (GSH/GSSG E $\mathrm{E}_{\mathrm{h}}$ ); (C) Glutathione peroxidase (GPx) activity; (D) Glutathione reductase (GR) activity; (E) Glutathione transferase (GST) activity; (F) Glutamate-cysteine ligase (GCL) activity. * Represents the effect of DAY across other factors $(p \leq 0.05)$.

In the distal jejunal mucosa (Table 6, Figure 3), QUE significantly affected the GSH concentration irrespective of the day post-weaning. Here, GSH levels were found to be decreased with $27 \%$ in treatment QUE300, as compared to QUE0. This decrease was not associated with any other change in the activity of GSH-related enzymes. The activity of GPx, GR, GST and GCL were unaffected by QUE or DAY $\times$ QUE $(p>0.05)$. Finally, although the GSSG levels were not different between dietary treatments, the altered GSH levels did translate in an altered GSH/GSSG $E_{h}$. Similar to the duodenal mucosa, the distal jejunal GSH/GSSG $\mathrm{E}_{\mathrm{h}}$ indicated a more oxidized GSH redox status on $\mathrm{d} 5$ versus d14 post-weaning $(+18 \mathrm{mV}: p<0.001)$. This was caused by significantly lower GSH levels $(-35 \%)$ and significantly higher GSSG levels $(+53 \%)$ on d5 versus d14 post-weaning. Strangely, the activity of the different GSH related enzymes did not correlate with this observation, since the GCL and GR activity were found to be increased by respectively $69 \%$ and $20 \%$ on d5 versus d 14 post-weaning, and GPx and GST activity were not affected by DAY $(p>0.05)$.

Table 6. Significance levels for treatment effects on the glutathione redox system in the distal jejunal mucosa of piglets at d5 and d14 post-weaning (DAY), fed a diet containing either 0, 100, 300, or $900 \mathrm{mg}$ quercetin $/ \mathrm{kg}$ diet (QUE) during the first $14 \mathrm{~d}$ post-weaning $(n=8)$.

\begin{tabular}{cccccccc}
\hline$p$-Value & GPx & GR & GST & GCL & GSH & GSSG & GSH/GSSG E $_{\mathbf{h}}$ \\
\hline DAY & 0.976 & 0.009 & 0.367 & 0.002 & $<0.001$ & 0.021 & $<0.001$ \\
QUE & 0.373 & 0.101 & 0.694 & 0.176 & 0.050 & 0.567 & 0.455 \\
DAY $\times$ QUE & 0.561 & 0.492 & 0.347 & 0.480 & 0.644 & 0.979 & 0.853 \\
\hline
\end{tabular}



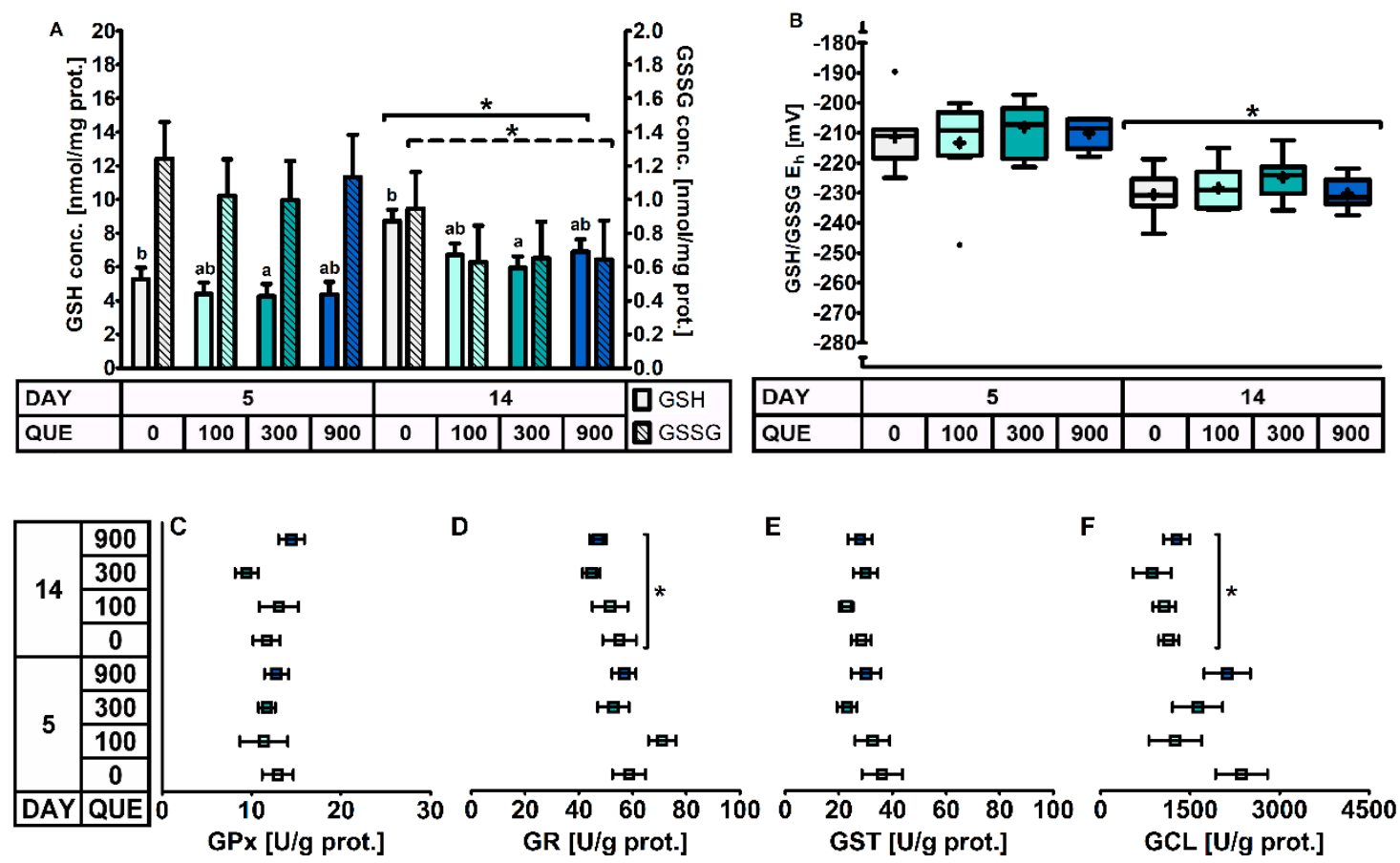

Figure 3. The glutathione redox system in the distal jejunal mucosa of piglets at $\mathrm{d} 5$ and $\mathrm{d} 14$ post-weaning (DAY), fed a diet containing 0, 100, 300, or $900 \mathrm{mg}$ quercetin/ $\mathrm{kg}$ diet (QUE) during the first 14d post-weaning. Results are presented as least squares means with SD. Significance levels of main effects and interaction terms are presented in Table 6: (A) glutathione (GSH) and glutathione disulphide (GSSG) concentrations; (B) Glutathione redox status (GSH/GSSG $E_{h}$ ); (C) Glutathione peroxidase (GPx) activity; (D) Glutathione reductase (GR) activity; (E) Glutathione transferase (GST) activity; (F) Glutamate-cysteine ligase (GCL) activity. * Represents the effect of DAY across other factors $(p \leq 0.05)$.

\subsubsection{The Hepatic Glutathione Redox System}

In the liver (Table 7, Figure 4), quercetin supplementation induced a higher GST activity on d5 post-weaning (DAY $\times$ QUE: $p=0.036$ ), where GST activity increased with $37 \%$ in QUE100, $48 \%$ in QUE300 and 47\% in QUE900, as compared to the control (QUE0). GST activity was not affected by QUE on d14 post-weaning $(p>0.05)$. On average, the GST activity was $78 \%$ lower on $\mathrm{d} 14$ versus d5 post-weaning (DAY: $p<0.01$ ). No other effects of quercetin supplementation on the hepatic GSH redox system were observed $(p>0.05)$. Similar to blood and small intestinal mucosa, piglets on $\mathrm{d} 5$ post-weaning exhibited a more oxidized GSH redox status $(+14 \mathrm{mV}, p<0.001)$ in the liver. This resulted from significantly higher hepatic GSSG levels $(+126 \%)$ on d5 versus d14 post-weaning, since GSH levels were not different between those two days $(p>0.05)$. These observations were peculiarly linked with a decrease and not an increase in GPx activity on d5 post-weaning. The four-fold higher GST activity on $\mathrm{d} 5$ post-weaning, irrespective of dietary treatment, does however point towards a different GSH utilization, and thus a potential loss of hepatic GSH on d5 post-weaning. Finally, the activity of GR and GCL were not significantly affected by DAY. 
Table 7. Significance levels for treatment effects on the glutathione redox system in lever tissue of piglets at d5 and d14post-weaning (DAY), fed a diet containing 0, 100, 300, or $900 \mathrm{mg}$ quercetin/ $\mathrm{kg}$ diet (QUE) during the first 14d post-weaning $(n=8)$.

\begin{tabular}{cccccccc}
\hline$p$-Value. & GPx & GR & GST & GCL & GSH & GSSG & GSH/GSSG E $_{\mathbf{h}}$ \\
\hline DAY & $<0.001$ & 0.297 & $<0.001$ & 0.546 & 0.258 & $<0.001$ & $<0.001$ \\
QUE & 0.775 & 0.309 & 0.018 & 0.905 & 0.584 & 0.485 & 0.428 \\
DAY $\times$ QUE & 0.519 & 0.463 & 0.036 & 0.745 & 0.864 & 0.864 & 0.988 \\
\hline
\end{tabular}
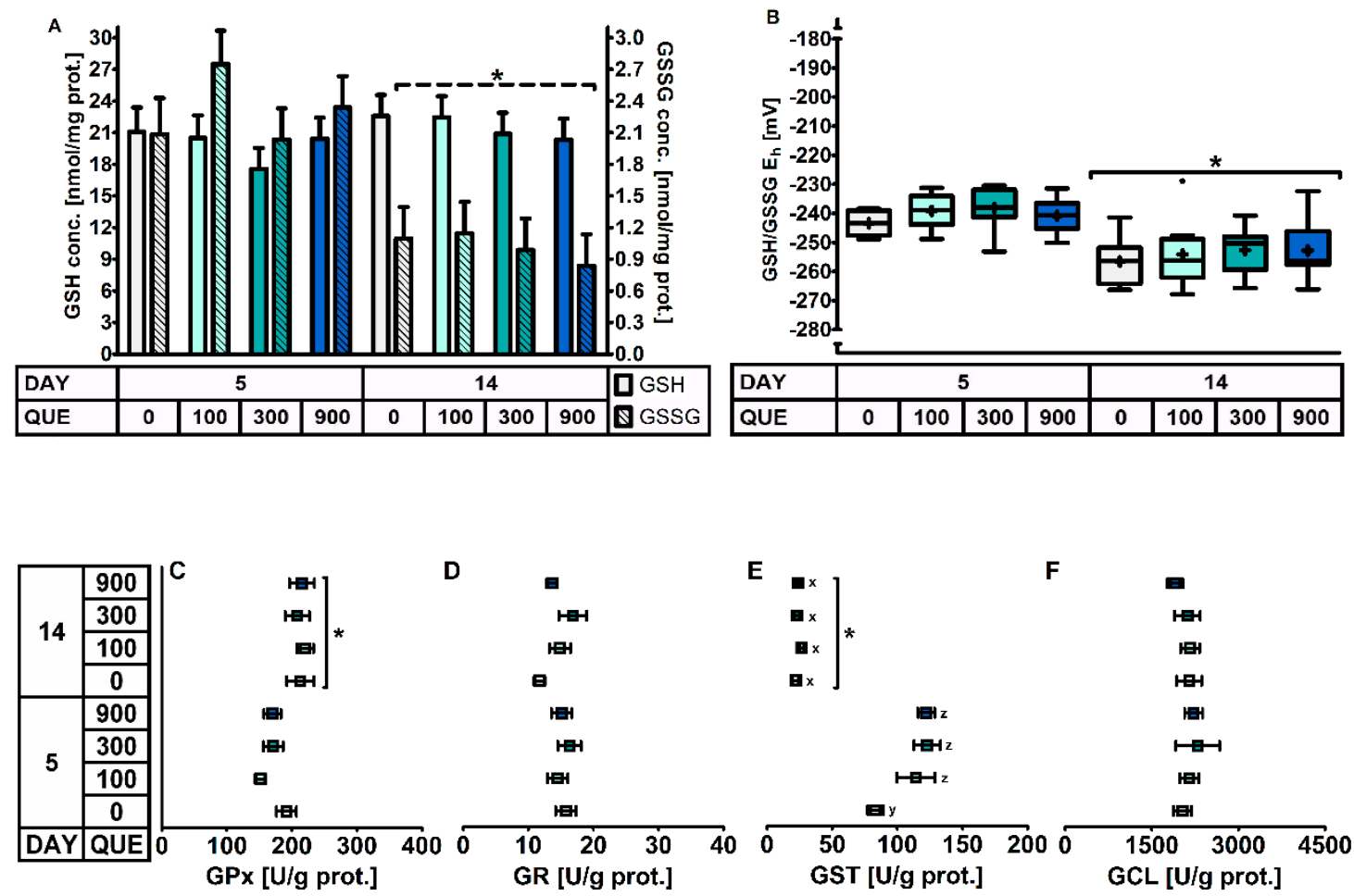

Figure 4. The glutathione redox system in the liver of piglets at $\mathrm{d} 5$ and $\mathrm{d} 14$ post-weaning (DAY), fed a diet containing either $0,100,300$, or $900 \mathrm{mg}$ quercetin/kg diet (QUE) during the first $14 \mathrm{~d}$ post-weaning. Results are presented as least squares means with SD. Significance levels of main effects and interaction terms are presented in Table 7: (A) glutathione (GSH) and glutathione disulphide (GSSG) concentrations;

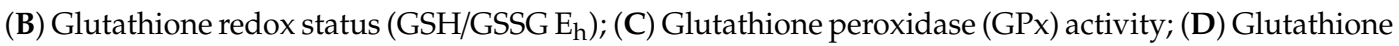
reductase (GR) activity; (E) Glutathione transferase (GST) activity; (F) Glutamate-cysteine ligase (GCL) activity. ${ }^{*}$ Represents the effect of DAY across other factors $(p \leq 0.05) .{ }^{\mathrm{x}, \mathrm{y}, \mathrm{z}}$ Represents the effect of QUE $\times \operatorname{DAY}(p \leq 0.05)$.

\subsection{Small Intestinal Histomorphology and Barrier Function}

Both in the duodenal and the distal jejunum, quercetin supplementation did not affect the histomorphological characteristics (Table 8). Villus length, villus width, crypt depth, and villus/crypt ratio were not altered by QUE $(p>0.05)$ or DAY $\times$ QUE $(p>0.05)$. Likewise, the protein abundance of PCNA and Caspase-3, measured in the distal jejunal mucosa, did not differ (QUE: $p>0.05$; DAY $\times$ QUE: $p>0.05$ ). These proteins are respectively involved in cell proliferation and apoptotic cell death, and thus indicate that quercetin did not alter cellular turnover in the jejunal mucosa. On the other hand, villus width in the distal jejunum increased with $9 \%$ on d14 versus d5 post-weaning $(p \leq 0.05)$. Also, crypts were on average $25 \%$ deeper on d 14 compared to d5 post-weaning (DAY: $p<0.001$ ), both in the duodenum and the distal jejunum. Although villus length did not differ between $\mathrm{d} 5$ and $\mathrm{d} 14$ post-weaning at both intestinal sites $(p>0.05)$, the difference in crypt depth resulted in approximately a $20 \%$ reduction in villus/crypt ratio on d14 versus $\mathrm{d} 5$ post-weaning $(p \leq 0.05)$. 
Table 8. The effect of quercetin at doses of either $0,100,300$, or $900 \mathrm{mg} / \mathrm{kg}$ diet (QUE) during the first $14 \mathrm{~d}$ post-weaning on the small intestinal histomorphology, barrier function and tight junction and mitotic/apoptotic protein abundance in piglets at d5 and d14post-weaning (DAY) $(n=8)$.

\begin{tabular}{|c|c|c|c|c|c|c|c|c|c|c|c|c|}
\hline \multirow{2}{*}{$\begin{array}{l}\text { DAY } \\
\text { QUE }\end{array}$} & \multicolumn{4}{|c|}{5} & \multicolumn{4}{|c|}{14} & \multirow{2}{*}{ SEM } & \multicolumn{3}{|c|}{$p$-Value } \\
\hline & 0 & 100 & 300 & 900 & 0 & 100 & 300 & 900 & & DAY & QUE & DAY $\times$ QUE \\
\hline \multicolumn{13}{|c|}{ Duodenum } \\
\hline Villus width $[\mu \mathrm{m}]$ & 97 & 105 & 97 & 102 & 97 & 94 & 96 & 105 & 2 & 0.154 & 0.702 & 0.597 \\
\hline Crypt depth $[\mu \mathrm{m}]$ & 215 & 271 & 199 & 253 & 210 & 249 & 206 & 267 & 4 & $<0.001$ & 0.424 & 0.791 \\
\hline Villus/crypt ratio $[\mu \mathrm{m} / \mu \mathrm{m}]$ & 1.19 & 0.94 & 1.34 & 1.01 & 1.17 & 1.00 & 1.20 & 1.13 & 0.03 & 0.001 & 0.492 & 0.456 \\
\hline Villus length $[\mu \mathrm{m}]$ & 220 & 252 & 268 & 224 & 177 & 224 & 198 & 262 & 9 & 0.180 & 0.350 & 0.177 \\
\hline Villus width $[\mu \mathrm{m}]$ & 87 & 93 & 87 & 95 & 86 & 86 & 78 & 101 & 2 & 0.010 & 0.697 & 0.135 \\
\hline Crypt depth $[\mu \mathrm{m}]$ & 159 & 211 & 164 & 203 & 154 & 206 & 256 & 219 & 4 & $<0.001$ & 0.911 & 0.832 \\
\hline Villus/crypt ratio $[\mu \mathrm{m} / \mu \mathrm{m}]$ & 1.39 & 1.21 & 1.62 & 1.12 & 1.16 & 1.10 & 1.27 & 1.21 & 0.05 & 0.046 & 0.409 & 0.384 \\
\hline PCNA [fmol/mg prot.] & 3.23 & 4.08 & 3.26 & 4.57 & 3.22 & 4.12 & 3.12 & 4.37 & 0.19 & 0.007 & 0.956 & 0.966 \\
\hline
\end{tabular}

$\mathrm{P}_{\mathrm{app}}=$ apparent permeability coefficient, FD4 = fluorescein isothiocyanate dextran, PCNA = proliferating cell nuclear antigen.

The FD4 flux across the distal jejunal mucosa, as a marker for epithelial paracellular transport, was not affected by QUE and DAY $\times$ QUE $(p>0.05)$. Likewise, the protein abundance of occludin, a major component of tight junction protein complex, was not altered by quercetin supplementation (QUE: $p>0.05$; DAY $\times$ QUE: $p>0.05$ ). It must also be noted that the distal jejunal FD4 flux was not affected by DAY $(p>0.05)$, potentially signifying that the distal jejunal barrier function was not compromised during the weaning transition. Still, the distal jejunal occludin protein abundance was two-fold higher on d5 versus d14 post-weaning $(p \leq 0.05)$.

\subsection{Principal Component Analysis}

A first PCA was executed, including all measurements on the GSH redox system at d5 and d14 post-weaning ( 23 variables), in order to evaluate if an overall response of dietary quercetin could be deduced. The first two principal components (PC) explained 17.6 and $15.5 \%$ of the variance. The subject score plot for PC1 vs. PC2 is shown in Figure 5A, and component loadings are presented in Figure 5B. Here, it seems that the objects did not cluster according to dietary treatment on $\mathrm{d} 5$ nor $\mathrm{d} 14$ post-weaning. This was statistically confirmed, as QUE and DAY $\times$ QUE did not affect the scores for PC1 and PC2 $(p>0.05)$. In contrast, subjects clearly clustered according to the day post-weaning. DAY had a significant effect on the scores for PC1 and PC2 $(p<0.001)$. The highest loadings in PC1 were the hepatic GSSG level $(r=0.818)$, the plasma GST activity $(r=0.679)$, the duodenal GR activity $(r=0.647)$ and hepatic GST activity $(r=0679)$. Piglets on $d 5$ post-weaning were thus characterized by higher hepatic GSSG levels, and increased activities of plasma and liver GST and duodenal GR. The most important loadings in PC2 were the hepatic GPx activity $(\mathrm{r}=0.743)$, the duodenal GSH level $(r=0.707)$ and the hepatic GSH level $(r=0.634)$. The decreased levels of duodenal and hepatic GSH, and the lower GPx activity in the liver, are indicative for piglets at $\mathrm{d} 5$ versus d14 post-weaning.

The data on small intestinal histomorphology, mucosal protein abundance and barrier function were subjected to a second, separate PCA analysis (10 variables; results not shown). The first two principal components explained $51.8 \%$ of the variance (Figure 6A). PC1 predominantly contained high positive loadings for histomorphological characteristics, while PC2 was dominated by high positive loadings for the distal jejunal protein abundance of PCNA, Caspase-3 and occludin (Figure 6B). The distal jejunal FD4 flux received a relative low loading in both PC1 and PC2 $(\mathrm{r}<0.200)$. Also here, subjects did not cluster according to dietary treatment, and neither QUE nor DAY $\times$ QUE influenced the scores for PC1 and PC2 ( $p>0.05)$. Subjects did however visually cluster according to the day post-weaning. Only PC1 was significantly affected by DAY $(p<0.001)$. Consequently, d5 and d14 
post-weaning could be clearly differentiated from each other based on histomorphological characteristics of the small intestine, rather than the barrier function or mitotic/apoptotic protein abundance.

A

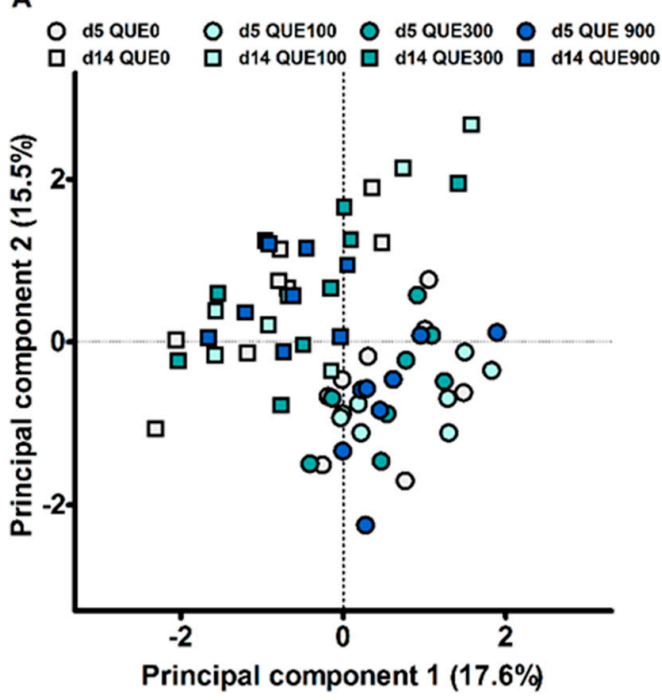

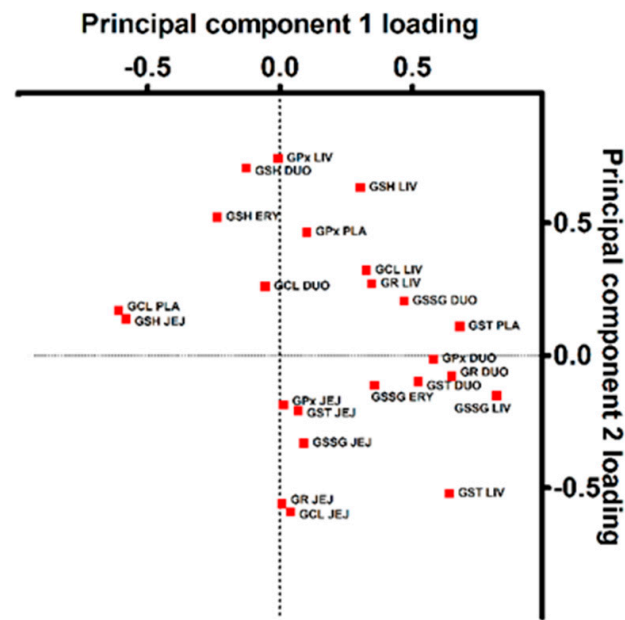

Figure 5. Principal component analysis of glutathione redox system in four different tissues of piglets at d5 and d14 post-weaning (DAY), fed a diet containing either 0, 100, 300, or $900 \mathrm{mg}$ quercetin/ $\mathrm{kg}$ diet (QUE) during the first 14d post-weaning: (A) Scores plot representing the 64 individual piglets in the multivariate space of the first two principal components. Animals can be visually clustered according to day post-weaning (d5 or d14). (B) Loading plot of the two major principal components. $\mathrm{GPx}=$ glutathione peroxidase, $\mathrm{GR}=$ glutathione reductase, $\mathrm{GST}=$ glutathione transferase; GCL = glutamate-cysteine ligase; GSH = glutathione; GSSG = glutathione dissulphide; PLA = plasma; ERY = erythrocyte; $\mathrm{DUO}=$ duodenum; JEJ = distal jejunum; LIV = liver.

A

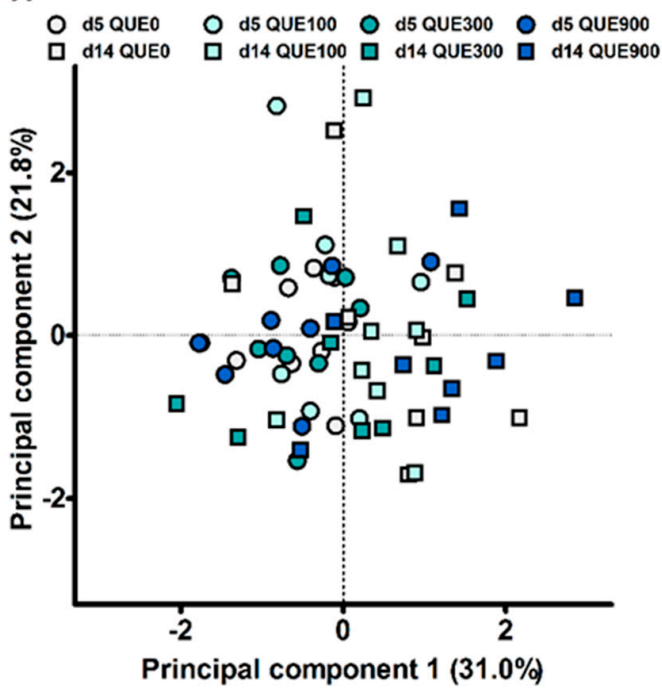

B

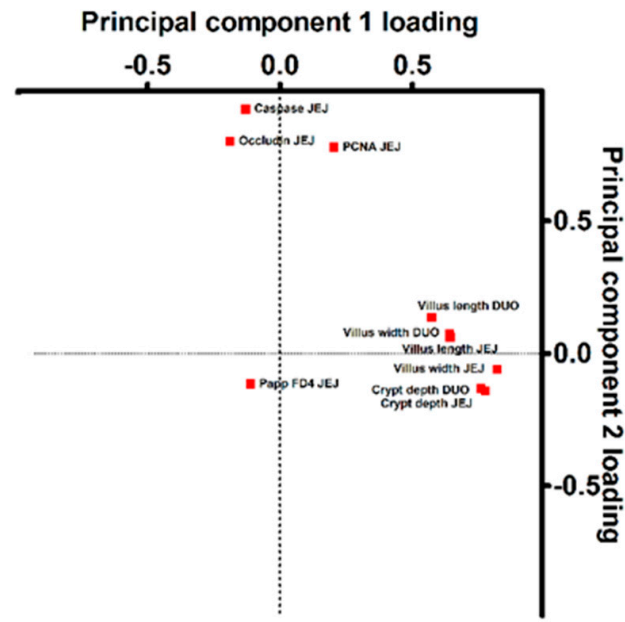

Figure 6. Principal component analysis of gut health parameters in the duodenum and distal jejunum of piglets at $\mathrm{d} 5$ and $\mathrm{d} 14$ post-weaning (DAY), fed a diet containing either $0,100,300$, or $900 \mathrm{mg}$ quercetin/ $\mathrm{kg}$ diet (QUE) during the first 14d post-weaning: (A) Scores plot representing the 64 individual piglets in the multivariate space of the first two principal components. Animals can be visually clustered according to day post-weaning (d5 or d14). (B) Loading plot of the two major principal components. $\mathrm{DUO}=$ duodenum; JEJ = distal jejunum; PCNA = proliferating cell nuclear antigen; Papp = apparent permeability coefficient; FD4 = fluorescein isothiocyanate dextran. 


\section{Discussion}

\subsection{Quercetin Supplementation Promoted the Hepatic GST Activity in the Occurrence of Oxidative Stress}

Effects of quercetin on the GSH redox status have been most often studied in experimental models for colitis in rats. Several of these studies report increased colonic mucosal GSH levels when quercetin or its glycosides are orally provided $[29,30,54]$. This effect, however, seems to depend on the dose of quercetin. Sánchez de Medina et al. (1996) [28] for example applied doses of 0.125, 0.25, 0.5, 1, 5, 10, 25 and $50 \mathrm{mg}$ quercetin per $\mathrm{kg}$ body weight, and found that only 5 and $10 \mathrm{mg} / \mathrm{kg}$ increased GSH in the colon. A dose-response study by Cruz et al. (1997) [27], although using rutin and not quercetin, found quite similar doses to be effective. Doses of 5 to $25 \mathrm{mg} / \mathrm{kg}$ body weight were effective in increasing colonic GSH levels. Levels of $25 \mathrm{mg}$ quercitrin $/ \mathrm{kg}$ were also found to be effective after three days of oral administration in rats that were not subjected to an experimental model of colitis, but GSH values normalized four days later [55]. This study also reported increased GSH levels in the ileal mucosa, whereas jejunal concentrations remained unaffected. Meyers et al. (2008) [56] further demonstrated that also hepatic GSH can be altered by quercetin administration in unchallenged mice, and this was shown to depend on the food source or glycosidic moiety linked to the quercetin molecule. Dietary quercetin but not rutin or quercetin glycosides from onion and apple peels, applied at an equal dose of $200 \mathrm{mg}$ quercetin per $\mathrm{kg}$ diet, increased hepatic GSH levels after seven days of administration. In the current study, doses of 100 to $900 \mathrm{mg}$ quercetin per $\mathrm{kg}$ diet, equal to 2.5-25 mg quercetin/ $\mathrm{kg}$ body weight, were applied in pigs. The hepatic GSH and GSSG levels, and consequently the GSH/GSSG $E_{h}$, were however not altered by quercetin supplementation.

It was remarkable that the hepatic GST activity increased at $\mathrm{d} 5$ post-weaning when quercetin was added to the diet. This could relate to the phase II metabolism of quercetin by GST in the liver, where glutathionylation of quercetin takes place in order to promote its excretion [57]. Several glutathionylated quercetin metabolites have already been identified in murine hepatic suspensions and in human urine [58]. Quercetin yet only increased the hepatic GST activity at d5 post-weaning. Values on d14 post-weaning were low and were not affected by quercetin supplementation. The previously cited authors [58] also mention that conjugation reactions between quercetin and GSH occur spontaneously and are not accelerated by GST (unpublished results). Even more, some in vitro work demonstrated that quinone-type oxidation products of quercetin can make covalent modifications to certain cysteine residues of GST, and thereby inhibit its activity. These modifications were also found to be reversible, and for instance, ascorbic acid and GSH could prevent this inhibition [12]. Connected to this, one in vivo study reported decreased hepatic GST activities when $2000 \mathrm{mg}$ quercetin per $\mathrm{kg}$ diet was fed to rats for three weeks [11]. This points out that, although quercetin is known as a powerful antioxidant, certain conditions can lead to a pro-oxidant behavior of quercetin and its derivates. This behavior was particularly prompted in a Fenton-like reaction system [59].

The pro-oxidant nature of quercetin has also been linked to the ability to upregulate GSH synthesis by altering GCL activity $[9,10]$. The exact mode of action still is not fully elucidated, but it was proposed to be associated with the feedback regulation of GCL when oxidized quercetin radicals cause GSH depletion [60,61]. In our study, we did not observe evidence for this. GCL activities remained unaffected in all measured tissues. Distal jejunal GSH levels were decreased when $300 \mathrm{mg}$ quercetin/kg diet was supplied, but not at doses of 100 or $900 \mathrm{mg} / \mathrm{kg}$. The unaltered MDA levels and further lack of treatment effect on the GSH redox system do not support that quercetin exhibited such an effect in the current experiment. An alternative mode of action depicts that oxidized quercetin radicals can react with thiols of important cell signaling proteins such as Kelch-like ECH-associated protein 1 (Keap1). The redox status of Keap1 affects its binding affinity for Nuclear factor erythroid 2-related factor 2 (Nrf2). The subsequent release and translocation of Nrf2 to the nucleus leads to the transcriptional upregulation of the antioxidant response $[9,10]$. In our study, we did not detect upregulated GPx, GR or GCL activities by quercetin, nor did the PCA analysis showed an overall change in the GSH redox system when quercetin was supplemented. We only observed a specific 
change in the hepatic GST activity on d5 post-weaning when quercetin was supplemented. This was recently also observed by Gao et al. (2017), when feeding a particularly high dose of $5000 \mathrm{mg} / \mathrm{kg}$ diet to rats for 6 weeks (1665) [13]. Transcriptional upregulation of GST via the Keap1/Nrf2 signaling pathway is known to take place in an oxidative stress event [62,63], which supports our observations in the liver. The hepatic GSSG level was increased and consequently, the GSH redox status was more oxidized on d5 post-weaning, and the GST activity was increased in the control treatment on d5 versus d14 post- weaning. Quercetin thus further promoted GST upregulation in an oxidative stress event. This points out that the altered hepatic GST activity was not destined to facilitate quercetin elimination but intended to empower other functions of GST. For example, protein glutathionylation by GST could have assisted in post-translational protein regulation and cell signaling [64-66], or in the protection of critical protein thiols from irreversible oxidation [67]. The presence of protein-GSH mixed disulphides and the glutathionylation of specific target proteins were not investigated in our study and would have been valuable to confirm this statement. Earlier research did for instance already report altered protein glutathionylation profiles in mice when quercetin was added to the diet [56]. GST further could have been involved in the removal of xenobiotics such as lipid peroxidation products [68], but this could not be confirmed by our measurements. MDA values were not affected by quercetin throughout the experiment. Quercetin-rich onions however did demonstrate to influence plasma lipid profile of pigs when fed a high-fat diet $[69,70]$, which could relate to lower circulating levels of MDA-modified low density lipoprotein, and thus a reduced risk for coronary heart disease [71]. With regard to the small intestine, although we observed a more oxidized GSH redox pool and an increased distal jejunal GST activity on d5 post-weaning, quercetin did not further upregulate small intestinal GST as observed in the liver.

\subsection{Quercetin Supplementation Did not Improve the Small Intestinal Functionality}

Numerous in vivo studies, almost exclusively in rodents, have tested the health benefits of flavonols in pro-inflammatory diseases such as chronic inflammatory bowel disease [2,3]. These insights are valuable since weaned piglets endure a pathology that, to a certain extent, parallels with a condition of inflammatory bowel disease. For instance, newly weaned piglets typically display poor growth or even weight loss during the first five days post-weaning [72], and this is often followed by a surge of diarrhea [73]. This was also observed in the current study and aligns with the outcome of several different experimental models for colitis in rodents [28,29,36,74,75]. Importantly, Galvez et al. (1993a; 1993b; 1995) demonstrated that dietary quercetin and quercitrin at doses of 25 to $50 \mathrm{mg} / \mathrm{kg}$ body weight could reduce diarrhea prevalence in challenged rodents [32-34]. Further investigation indicated that the effects of quercitrin were attributed to quercetin release generated after glycoside cleavage by the intestinal microbiota [76]. These doses of quercetin were quite similar to the dose range in the current study, where quercetin was supplemented at 100 to $900 \mathrm{mg} / \mathrm{kg} \operatorname{diet}(2.5-25 \mathrm{mg} / \mathrm{kg}$ body weight). However, we did not observe a similar effect during the weaning transition of piglets. This could be due to the different etiology, whereas in piglets, diarrhea is typically associated with malabsorption [77] and the proliferation of enterotoxigenic Escherichia coli (ETEC) in the intestine [78].

Besides diarrhea, experimentally induced colitis in rodents also results in epithelial degeneration in the colon $[74,75,79]$. Similar in the pig, weaning is followed by instantaneous villus atrophy and crypt hyperplasia in the small intestine. In both cases this indicates an increased rate of cell loss and/or a reduced rate of cell renewal [80]. In the current study, weaning-induced villus atrophy most probably did occur [81], but this could not be confirmed by comparing d5 with d14 post-weaning. The deeper crypts at both intestinal sites and the higher protein abundance of PCNA and caspase-3 in the distal jejunum at $\mathrm{d} 5$ post-weaning do substantiate that a process of damage and recovery took place in the small intestine upon weaning. Quercetin supplementation, yet, did not impact on the histological characteristics of the small intestine, and neither did it influence the PCNA or caspase-3 protein abundance in the distal jejunum. The PCA analysis could further only differentiate the subjects according to the day post-weaning. This indicates that the beneficial effects of quercetin in 
the colon [24,26,29-31,35,62,82] and the small intestine [62], observed in experimentally challenged rodents, are not easily translated to the weaner pig. One study in pigs did observe an increased jejunal villus length by dietary quercetin supplementation $(25 \mathrm{mg} / \mathrm{kg}$ diet $)$ prior to the induction of transport stress, and also reported altered jejunal tight junction mRNA expression [22]. Indeed, quercetin is also considered to modulate the tight junction distribution, either via directly interacting with intracellular signaling molecules such as protein kinases [83,84], or through the GSH-modulating properties of quercetin and its consequences on multiple facets of tight junction regulation [15]. In our study, the distal jejunal barrier function did not differ between the dietary treatments. Likewise, the small intestinal GSH redox system was not affected by quercetin, not even in the event of oxidative stress at $\mathrm{d} 5$ post-weaning. This suggests that redox regulation of cell cycling $[17,18]$ and tight junction distribution $[15,83,84]$ was not affected by quercetin in our trial.

\section{Conclusions}

The data presented in this study demonstrate that quercetin, supplemented at 100, 300 and $900 \mathrm{mg} / \mathrm{kg}$ diet, upregulated the hepatic GST activity at d5 post-weaning, when piglets experienced redox disturbance in the liver and small intestinal mucosa. This potentially amplified protein glutathionylation or xenobiotic conjugation, which are important instruments in the response to redox disturbance. This effect was however not observed in the small intestinal mucosa. Quercetin also did not prevent intestinal damage upon weaning, nor did it support intestinal recovery until d14 post-weaning. As a result, quercetin supplementation did not improve animal performance or health during the weaning transition.

Author Contributions: S.D.S., C.V.G. and J.M. were involved in conceptualization and funding acquisition. J.D., S.D.S., C.V.G. and J.M. were involved in validation, supervision, project administration and obtaining resources. J.D. was involved in presentation of the original draft manuscript. J.D., H.V., N.V.N., W.W., S.D.S., C.V.G. and J.M. were involved in experimental design, methodology, formal analysis, data curation, writing, reviewing and editing the manuscript.

Funding: This research was funded by the Flemish Agency for Innovation by Science and Technology (IWT-LO 100856).

Acknowledgments: We thank Katty Huybrechts, Gunther Vrolix, Karen Jennes, Tessa Van Der Eecken, Geoffrey Verhofsté, Ann Ovyn, Sabine Coolsaet, Daisy Baeyens, Erik Claeys, Thomas Spranghers, Claudio Forté, Ping Zheng and Honglin Yan for their skillful technical assistance, and Ziyu Ma for her dedication, support and scientific contribution to this study.

Conflicts of Interest: The authors declare no conflict of interest. The funders had no role in the design of the study; in the collection, analyses, or interpretation of data; in the writing of the manuscript, or in the decision to publish the results.

\section{References}

1. Miles, S.L.; McFarland, M.; Niles, R.M. Molecular and physiological actions of quercetin: Need for clinical trials to assess its benefits in human disease. Nutr. Rev. 2014, 72, 720-734. [CrossRef] [PubMed]

2. Vezza, T.; Rodriguez-Nogales, A.; Algieri, F.; Utrilla, M.P.; Rodriguez-Cabezas, M.E.; Galvez, J. Flavonoids in inflammatory bowel disease: A review. Nutrients 2016, 8, 211. [CrossRef] [PubMed]

3. Salaritabar, A.; Darvishi, B.; Hadjiakhoondi, F.; Manayi, A.; Sureda, A.; Nabavi, S.F.; Fitzpatrick, L.R.; Nabavi, S.M.; Bishayee, A. Therapeutic potential of flavonoids in inflammatory bowel disease: A comprehensive review. World J. Gastroenterol. 2017, 23, 5097-5114. [CrossRef] [PubMed]

4. Stokes, C.R.; Bailey, M.; Haverson, K.; Harris, C.; Jones, P.; Inman, C.; Pié, S.; Oswald, I.P.; Williams, B.A.; Akkermans, A.D.L.; et al. Postnatal development of intestinal immune system in piglets: Implications for the process of weaning. Anim. Res. 2004, 53, 325-334. [CrossRef]

5. Wijtten, P.J.A.; van der Meulen, J.; Verstegen, M.W.A. Intestinal barrier function and absorption in pigs after weaning: A review. Br. J. Nutr. 2011, 105, 967-981. [CrossRef] [PubMed]

6. Boudry, G.; Peron, V.; Le Huerou-Luron, I.; Lalles, J.P.; Seve, B. Weaning induces both transient and long-lasting modifications of absorptive, secretory, and barrier properties of piglet intestine. J. Nutr. 2004, 134, 2256-2262. [CrossRef] 
7. Yazdankhah, S.; Rudi, K.; Bernhoft, A. Zinc and copper in animal feed - development of resistance and co-resistance to antimicrobial agents in bacteria of animal origin. Microb. Ecol. Health Dis. 2014, 25. [CrossRef]

8. Vergauwen, H.; Prims, S.; Degroote, J.; Wang, W.; Casteleyn, C.; Van Cruchten, S.; De Smet, S.; Michiels, J.; Van Ginneken, C. In vitro investigation of six antioxidants for pig diets. Antioxidants 2016, 5, 41. [CrossRef]

9. Myhrstad, M.C.; Carlsen, H.; Nordstrom, O.; Blomhoff, R.; Moskaug, J.O. Flavonoids increase the intracellular glutathione level by transactivation of the gamma-glutamylcysteine synthetase catalytical subunit promoter. Free Radic. Biol. Med. 2002, 32, 386-393. [CrossRef]

10. Moskaug, J.Ø.; Carlsen, H.; Myhrstad, M.C.; Blomhoff, R. Polyphenols and glutathione synthesis regulation. Am. J. Clin. Nutr. 2005, 81, 277S-283S. [CrossRef]

11. Wiegand,H.; Boesch-Saadatmandi, C.; Regos, I.; Treutter, D.; Wolffram, S.; Rimbach, G. Effects of quercetin and catechin on hepatic glutathione-s transferase (gst), $\operatorname{nad}(\mathrm{p}) \mathrm{h}$ quinone oxidoreductase 1 (nqo1), and antioxidant enzyme activity levels in rats. Nutr. Cancer 2009, 61, 717-722. [CrossRef] [PubMed]

12. van Zanden, J.J.; Ben Hamman, O.; van Iersel, M.L.P.S.; Boeren, S.; Cnubben, N.H.P.; Lo Bello, M.; Vervoort, J.; van Bladeren, P.J.; Rietjens, I.M.C.M. Inhibition of human glutathione s-transferase p1-1 by the flavonoid quercetin. Chem. Biol. Interact. 2003, 145, 139-148. [CrossRef]

13. Gao, W.; Pu, L.; Chen, M.; Wei, J.; Xin, Z.; Wang, Y.; Yao, Z.; Shi, T.; Guo, C. Glutathione homeostasis is significantly altered by quercetin via the keap1/nrf2 and mapk signaling pathways in rats. J. Clin. Biochem. Nutr. 2018, 62, 56-62. [CrossRef] [PubMed]

14. Rao, R.K.; Basuroy, S.; Rao, V.U.; Karnaky, K.J.; Gupta, A. Tyrosine phosphorylation and dissociation of occludin-zo-1 and e-cadherin-beta-catenin complexes from the cytoskeleton by oxidative stress. Biochem. J. 2002, 368, 471-481. [CrossRef] [PubMed]

15. Rao, R. Oxidative stress-induced disruption of epithelial and endothelial tight junctions. Front. Biosci. 2008, 13, 7210-7226. [CrossRef] [PubMed]

16. Rao, R.K.; Li, L.; Baker, R.D.; Baker, S.S.; Gupta, A. Glutathione oxidation and ptpase inhibition by hydrogen peroxide in caco-2 cell monolayer. Am. J. Physiol. Gastrointest. Liver Physiol. 2000, 279, 332-340. [CrossRef] [PubMed]

17. Jones, D.P. Redox sensing: Orthogonal control in cell cycle and apoptosis signalling. J. Intern. Med. 2010, 268, 432-448. [CrossRef] [PubMed]

18. Circu, M.L.; Aw, T.Y. Intestinal redox biology and oxidative stress. Semin. Cell Dev. Biol. 2012, 23, $729-737$. [CrossRef]

19. Degroote, J.; Michiels, J.; Claeys, E.; Ovyn, A.; De Smet, S. Changes in the pig small intestinal mucosal glutathione kinetics after weaning. J. Anim. Sci. 2012, 90, 359-361. [CrossRef]

20. Luo, Z.; Zhu, W.; Guo, Q.; Luo, W.; Zhang, J.; Xu, W.; Xu, J. Weaning induced hepatic oxidative stress, apoptosis, and aminotransferases through mapk signaling pathways in piglets. Oxid. Med. Cell Longev. 2016, 2016, 1-10. [CrossRef]

21. Luehring, M.; Blank, R.; Wolffram, S. Vitamin e-sparing and vitamin e-independent antioxidative effects of the flavonol quercetin in growing pigs. Anim. Feed Sci. Technol. 2011, 169, 199-207. [CrossRef]

22. Zou, Y.; Wei, H.K.; Xiang, Q.H.; Wang, J.; Zhou, Y.F.; Peng, J. Protective effect of quercetin on pig intestinal integrity after transport stress is associated with regulation oxidative status and inflammation. J. Vet. Med. Sci. 2016, 78, 1487-1494. [CrossRef] [PubMed]

23. Hein, E.M.; Rose, K.; van't Slot, G.; Friedrich, A.W.; Humpf, H.U. Deconjugation and degradation of flavonol glycosides by pig cecal microbiota characterized by fluorescence in situ hybridization (fish). J. Agric. Food Chem. 2008, 56, 2281-2290. [CrossRef] [PubMed]

24. Castangia, I.; Nacher, A.; Caddeo, C.; Merino, V.; Diez-Sales, O.; Catalan-Latorre, A.; Fernandez-Busquets, X.; Fadda, A.M.; Manconi, M. Therapeutic efficacy of quercetin enzyme-responsive nanovesicles for the treatment of experimental colitis in rats. Acta Biomater. 2015, 13, 216-227. [CrossRef] [PubMed]

25. Caddeo, C.; Nacher, A.; Diez-Sales, O.; Merino-Sanjuan, M.; Fadda, A.M.; Manconi, M. Chitosan-xanthan gum microparticle-based oral tablet for colon-targeted and sustained delivery of quercetin. J. Microencapsul 2014, 31, 694-699. [CrossRef] [PubMed]

26. Kwon, K.H.; Murakami, A.; Tanaka, T.; Ohigashi, H. Dietary rutin, but not its aglycone quercetin, ameliorates dextran sulfate sodium-induced experimental colitis in mice: Attenuation of pro-inflammatory gene expression. Biochem. Pharm. 2005, 69, 395-406. [CrossRef] 
27. Cruz, T.; Galvez, J.; Ocete, M.A.; Crespo, M.E.; Sanchez de Medina, L.H.F.; Zarzuelo, A. Oral administration of rutoside can ameliorate inflammatory bowel disease in rats. Life Sci. 1998, 62, 687-695. [CrossRef]

28. Sanchez de Medina, F.; Galvez, J.; Romero, J.A.; Zarzuelo, A. Effect of quercitrin on acute and chronic experimental colitis in the rat. J. Pharm. Exp. 1996, 278, 771-779.

29. Dodda, D.; Chhajed, R.; Mishra, J. Protective effect of quercetin against acetic acid induced inflammatory bowel disease (ibd) like symptoms in rats: Possible morphological and biochemical alterations. Pharm. Rep. 2014, 66, 169-173. [CrossRef]

30. Dodda, D.; Chhajed, R.; Mishra, J.; Padhy, M. Targeting oxidative stress attenuates trinitrobenzene sulphonic acid induced inflammatory bowel disease like symptoms in rats: Role of quercetin. Indian J. Pharm. 2014, 46, 286-291. [CrossRef]

31. Guazelli, C.F.S.; Fattori, V.; Colombo, B.B.; Georgetti, S.R.; Vicentini, F.T.M.C.; Casagrande, R.; Baracat, M.M.; Verri, W.A. Quercetin-loaded microcapsules ameliorate experimental colitis in mice by anti-inflammatory and antioxidant mechanisms. J. Nat. Prod. 2013, 76, 200-208. [CrossRef] [PubMed]

32. Galvez, J.; Crespo, M.E.; Jimenez, J.; Suarez, A.; Zarzuelo, A. Antidiarrhoeic activity of quercitrin in mice and rats. J. Pharm. Pharm. 1993, 45, 157-159. [CrossRef] [PubMed]

33. Galvez, J.; Sanchez de Medina, F.; Jimenez, J.; Torres, M.I.; Fernandez, M.I.; Nunez, M.C.; Rios, A.; Gil, A.; Zarzuelo, A. Effect of quercitrin on lactose-induced chronic diarrhoea in rats. Planta Med. 1995, 61, 302-306. [CrossRef] [PubMed]

34. Galvez, J.; Zarzuelo, A.; Crespo, M.E.; Lorente, M.D.; Ocete, M.A.; Jimenez, J. Antidiarrhoeic activity of euphorbia hirta extract and isolation of an active flavonoid constituent. Planta Med. 1993, 59, 333-336. [CrossRef] [PubMed]

35. Kim, H.; Kong, H.; Choi, B.; Yang, Y.; Kim, Y.; Lim, M.J.; Neckers, L.; Jung, Y. Metabolic and pharmacological properties of rutin, a dietary quercetin glycoside, for treatment of inflammatory bowel disease. Pharm Res. 2005, 22, 1499-1509. [CrossRef] [PubMed]

36. Perez-Vizcaino, F.; Duarte, J.; Santos-Buelga, C. The flavonoid paradox: Conjugation and deconjugation as key steps for the biological activity of flavonoids. J. Sci. Food Agric. 2012, 92, 1822-1825. [CrossRef] [PubMed]

37. Ader, P.; Wessmann, A.; Wolffram, S. Bioavailability and metabolism of the flavonol quercetin in the pig. Free Radic. Biol. Med. 2000, 28, 1056-1067. [CrossRef]

38. Crespy, V.; Morand, C.; Manach, C.; Besson, C.; Demigne, C.; Remesy, C. Part of quercetin absorbed in the small intestine is conjugated and further secreted in the intestinal lumen. Am. J. Physiol. 1999, 277, G120-G126. [CrossRef]

39. Cermak, R.; Landgraf, S.; Wolffram, S. The bioavailability of quercetin in pigs depends on the glycoside moiety and on dietary factors. J. Nutr. 2003, 133, 2802-2807. [CrossRef]

40. Bieger, J.; Cermak, R.; Blank, R.; de Boer, V.C.J.; Hollman, P.C.H.; Kamphues, J.; Wolffram, S. Tissue distribution of quercetin in pigs after long-term dietary supplementation. J. Nutr. 2008, 138, 1417-1420. [CrossRef]

41. de Boer, V.C.J.; Dihal, A.A.; van der Woude, H.; Arts, I.C.W.; Wolffram, S.; Alink, G.M.; Rietjens, I.M.C.M.; Keijer, J.; Hollman, P.C.H. Tissue distribution of quercetin in rats and pigs. J. Nutr. 2005, 135, 1718-1725. [CrossRef] [PubMed]

42. CVB. Data on Chemical Composition, Digestibility and Nutritive Value of Feedstuff; Centraal Veevoederbureau: Lelystad, The Netherlands, 1997.

43. Hernandez, P.; Zomeno, L.; Arino, B.; Blasco, A. Antioxidant, lipolytic and proteolytic enzyme activities in pork meat from different genotypes. Meat Sci. 2004, 66, 525-529. [CrossRef]

44. Carlberg, I.; Mannervik, B. Glutathione reductase. Methods Enzym. 1985, 113, 484-490.

45. Habig, W.H.; Jakoby, W.B. Assays for differentiation of glutathione s-transferases. Methods Enzym. 1981, 77, 398-405. [CrossRef]

46. White, C.C.; Viernes, H.; Krejsa, C.M.; Botta, D.; Kavanagh, T.J. Fluorescence-based microtiter plate assay for glutamate-cysteine ligase activity. Anal. Biochem. 2003, 318, 175-180. [CrossRef]

47. Grotto, D.; Santa Maria, L.D.; Boeira, S.; Valentini, J.; Charão, M.F.; Moro, A.M.; Nascimento, P.C.; Pomblum, V.J.; Garcia, S.C. Rapid quantification of malondialdehyde in plasma by high performance liquid chromatography-visible detection. J. Pharm Biomed. Anal. 2007, 43, 619-624. [CrossRef] [PubMed]

48. Walker, J.M. The bicinchoninic acid (bca) assay for protein quantitation. Methods Mol. Biol. 1994, 32, 5-8. [CrossRef] 
49. Yoshida, T. Determination of reduced and oxidized glutathione in erythrocytes by high-performance liquid chromatography with ultraviolet absorbance detection. J. Chromatogr. B Biomed. Appl. 1996, 678, 157-164. [CrossRef]

50. Degroote, J.; Van Noten, N.; Wang, W.; De Smet, S.; Michiels, J. Effects of n-acetyl-cysteine supplementation through drinking water on the glutathione redox status during the weaning transition of piglets. Antioxidants 2019, 8, 24. [CrossRef]

51. Degroote, J.; Wang, W.; Vergauwen, H.; De Smet, S.; Van Ginneken, C.; Michiels, J. Impact of a dietary challenge with peroxidized oil on the glutathione redox status and integrity of the small intestine in weaned piglets. Animal 2018, 1-10. [CrossRef]

52. Jones, D.P.; Sies, H. The redox code. Antioxid Redox Signal. 2015, 23, 734-746. [CrossRef] [PubMed]

53. Neirinckx, E.; Vervaet, C.; Michiels, J.; De Smet, S.; Van den Broeck, W.; Remon, J.P.; De Backer, P.; Croubels, S. Feasibility of the ussing chamber technique for the determination of in vitro jejunal permeability of passively absorbed compounds in different animal species. J. Vet. Pharm. 2011, 34, 290-297. [CrossRef] [PubMed]

54. Camuesco, D.; Comalada, M.; Rodriguez-Cabezas, M.E.; Nieto, A.; Lorente, M.D.; Concha, A.; Zarzuelo, A.; Galvez, J. The intestinal anti-inflammatory effect of quercitrin is associated with an inhibition in inos expression. Br. J. Pharm. 2004, 143, 908-918. [CrossRef] [PubMed]

55. Galvez, J.; de la Cruz, J.P.; Zarzuelo, A.; Sanchez de Medina, F., Jr.; Jimenez, J.; Sanchez de la Cuesta, F. Oral administration of quercitrin modifies intestinal oxidative status in rats. Gen. Pharm. 1994, 25, 1237-1243. [CrossRef]

56. Meyers, K.J.; Rudolf, J.L.; Mitchell, A.E. Influence of dietary quercetin on glutathione redox status in mice. J. Agric. Food Chem. 2008, 56, 830-836. [CrossRef] [PubMed]

57. Armstrong, R.N. Structure, catalytic mechanism, and evolution of the glutathione transferases. Chem. Res. Toxicol. 1997, 10, 2-18. [CrossRef] [PubMed]

58. Hong, Y.J.; Mitchell, A.E. Identification of glutathione-related quercetin metabolites in humans. Chem. Res. Toxicol. 2006, 19, 1525-1532. [CrossRef]

59. Kessler, M.; Ubeaud, G.; Jung, L. Anti- and pro-oxidant activity of rutin and quercetin derivatives. J. Pharm Pharm. 2003, 55, 131-142. [CrossRef]

60. Lu, S.C. Glutathione synthesis. Biochim. Biophys. Acta Gen. Subj. 2013, 1830, 3143-3153. [CrossRef]

61. Tian, L.; Shi, M.M.; Forman, H.J. Increased transcription of the regulatory subunit of gamma-glutamylcysteine synthetase in rat lung epithelial 12 cells exposed to oxidative stress or glutathione depletion. Arch. Biochem. Biophys. 1997, 342, 126-133. [CrossRef]

62. Sukhotnik, I.; Moati, D.; Shaoul, R.; Loberman, B.; Pollak, Y.; Schwartz, B. Quercetin prevents small intestinal damage and enhances intestinal recovery during methotrexate-induced intestinal mucositis of rats. Food Nutr. Res. 2018, 62. [CrossRef] [PubMed]

63. Carvalho, A.N.; Marques, C.; Guedes, R.C.; Castro-Caldas, M.; Rodrigues, E.; van Horssen, J.; Gama, M.J. S-glutathionylation of keap1: A new role for glutathione s-transferase pi in neuronal protection. Febs Lett. 2016, 590, 1455-1466. [CrossRef] [PubMed]

64. Dominko, K.; Dikic, D. Glutathionylation: A regulatory role of glutathione in physiological processes. Arh. Hig. Rada Toksikol. 2018, 69, 1-24. [CrossRef] [PubMed]

65. Circu, M.L.; Aw, T.Y. Redox biology of the intestine. Free Radic. Res. 2011, 45, 1245-1266. [CrossRef] [PubMed]

66. Townsend, D.M.; Manevich, Y.; He, L.; Hutchens, S.; Pazoles, C.J.; Tew, K.D. Novel role for glutathione s-transferase pi. Regulator of protein s-glutathionylation following oxidative and nitrosative stress. J. Biol. Chem. 2009, 284, 436-445. [CrossRef] [PubMed]

67. D'Autreaux, B.; Toledano, M.B. Ros as signalling molecules: Mechanisms that generate specificity in ros homeostasis. Nat. Rev. Mol. Cell Biol. 2007, 8, 813-824. [CrossRef] [PubMed]

68. Balogh, L.M.; Atkins, W.M. Interactions of glutathione transferases with 4-hydroxynonenal. Drug Metab. Rev. 2011, 43, 165-178. [CrossRef] [PubMed]

69. Ostrowska, E.; Gabler, N.K.; Sterling, S.J.; Tatham, B.G.; Jones, R.B.; Eagling, D.R.; Jois, M.; Dunshea, F.R. Consumption of brown onions (allium cepa var. Cavalier and var. Destiny) moderately modulates blood lipids, haematological and haemostatic variables in healthy pigs. Br. J. Nutr. 2004, 91, 211-218. [CrossRef]

70. Gabler, N.K.; Ostrowska, E.; Sterling, S.J.; Jones, R.B.; Tatham, B.G.; Eagling, D.R.; Jois, M.; Dunshea, F.R. Consumption of raw brown onions variably modulate plasma lipid profile and lipoprotein oxidation in pigs fed a high-fat diet. J. Sci. Food Agric. 2005, 85, 154-160. [CrossRef] 
71. Amaki, T.; Suzuki, T.; Nakamura, F.; Hayashi, D.; Imai, Y.; Morita, H.; Fukino, K.; Nojiri, T.; Kitano, S.; Hibi, N.; et al. Circulating malondialdehyde modified ldl is a biochemical risk marker for coronary artery disease. Heart 2004, 90, 1211-1213. [CrossRef]

72. Pluske, J.R.; Turpin, D.L.; Kim, J.C. Gastrointestinal tract (gut) health in the young pig. Anim. Nutr. 2018, 4, 187-196. [CrossRef] [PubMed]

73. Heo, J.M.; Opapeju, F.O.; Pluske, J.R.; Kim, J.C.; Hampson, D.J.; Nyachoti, C.M. Gastrointestinal health and function in weaned pigs: A review of feeding strategies to control post-weaning diarrhoea without using in-feed antimicrobial compounds. J. Anim. Physiol. Anim. Nutr. 2012. [CrossRef] [PubMed]

74. Chassaing, B.; Aitken, J.D.; Malleshappa, M.; Vijay-Kumar, M. Dextran sulfate sodium (dss)-induced colitis in mice. Curr. Protoc. Immunol. 2014, 104. [CrossRef]

75. Antoniou, E.; Margonis, G.A.; Angelou, A.; Pikouli, A.; Argiri, P.; Karavokyros, I.; Papalois, A.; Pikoulis, E. The tnbs-induced colitis animal model: An overview. Ann. Med. Surg. (Lond) 2016, 11, 9-15. [CrossRef] [PubMed]

76. Comalada, M.; Camuesco, D.; Sierra, S.; Ballester, I.; Xaus, J.; Galvez, J.; Zarzuelo, A. In vivo quercitrin anti-inflammatory effect involves release of quercetin, which inhibits inflammation through down-regulation of the nf-kappab pathway. Eur. J. Immunol. 2005, 35, 584-592. [CrossRef] [PubMed]

77. Miller, B.G.; Newby, T.J.; Stokes, C.R.; Bourne, F.J. Influence of diet on postweaning malabsorption and diarrhoea in the pig. Res. Vet. Sci. 1984, 36, 187-193. [CrossRef]

78. Rhouma, M.; Fairbrother, J.M.; Beaudry, F.; Letellier, A. Post weaning diarrhea in pigs: Risk factors and non-colistin-based control strategies. Acta Vet. Scand. 2017, 59, 31. [CrossRef] [PubMed]

79. Perse, M.; Cerar, A. Dextran sodium sulphate colitis mouse model: Traps and tricks. J. Biomed. Biotechnol. 2012, 2012, 718617. [CrossRef]

80. Pluske, J.R.; Hampson, D.J.; Williams, I.H. Factors influencing the structure and function of the small intestine in the weaned pig: A review. Livest. Prod. Sci. 1997, 51, 215-236. [CrossRef]

81. Al Masri, S.; Hünigen, H.; Al Aiyan, A.; Rieger, J.; Zentek, J.; Richardson, K.; Plendl, J. Influence of age at weaning and feeding regimes on the postnatal morphology of the porcine small intestine: A review of morphometric studies. J. Swine Health Prod. 2015, 23, 186-203. [CrossRef]

82. Hong, Z.; Piao, M. Effect of quercetin monoglycosides on oxidative stress and gut microbiota diversity in mice with dextran sodium sulphate-induced colitis. Biomed. Res. Int. 2018, 2018, 8343052. [CrossRef] [PubMed]

83. Suzuki, T.; Hara, H. Quercetin enhances intestinal barrier function through the assembly of zonula [corrected] occludens-2, occludin, and claudin-1 and the expression of claudin-4 in caco-2 cells. J. Nutr. 2009, 139, 965-974. [CrossRef] [PubMed]

84. Suzuki, T.; Hara, H. Role of flavonoids in intestinal tight junction regulation. J. Nutr. Biochem. 2011, 22, 401-408. [CrossRef] [PubMed]

(C) 2019 by the authors. Licensee MDPI, Basel, Switzerland. This article is an open access article distributed under the terms and conditions of the Creative Commons Attribution (CC BY) license (http://creativecommons.org/licenses/by/4.0/). 